Universidad de Lima

Facultad de Comunicación

Carrera de Comunicación

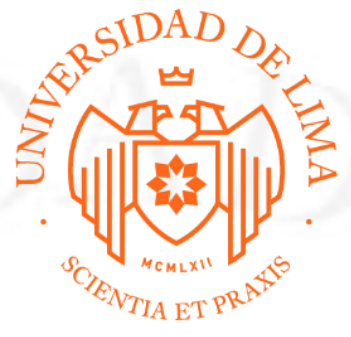

\title{
PISANDO TIERRA PODCAST
}

Trabajo de Suficiencia Profesional para optar el Título Profesional de Licenciado en Comunicación

María José Centeno Laurente

20130279@aloe.ulima.edu.pe

Monica Gabriela Falcon Paredes

20141789@aloe.ulima.edu.pe

\section{Asesor}

Carlos Vidal Rivadeneyra Olcese

$$
\text { Lima - Perú }
$$

18 de octubre de 2019 


\section{PISANDO TIERRA PODCAST}




\section{ÍNDICE}

\section{CAPÍTULO I: ANTECEDENTES DEL TRABAJO ....................................................4}

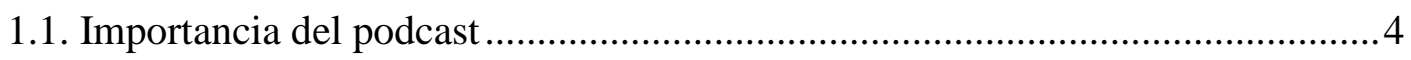

1.2. El podcast en el Perú....................................................................................

1.3. La sostenibilidad como temática de podcasts peruanos ..................................5

1.4. Análisis para la elección del público objetivo de Pisando Tierra ...................... 7

1.5. Los Objetivos de Desarrollo Sostenible en el contexto peruano...............8

CAPÍTULO II: REALIZACIÓN ..................................................................................... 14

2.1. Manual de marca de Pisando Tierra ............................................................. 16

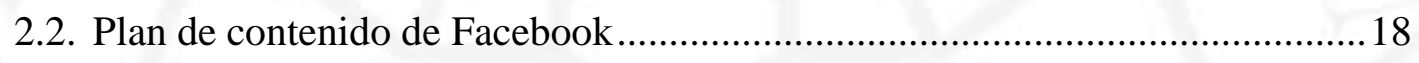

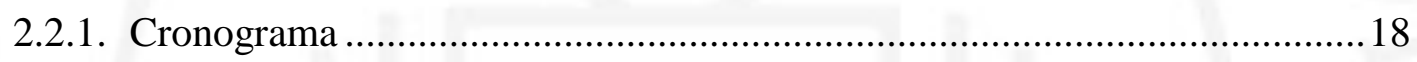

2.2.2. Formato de descripción en las publicaciones ........................................... 18

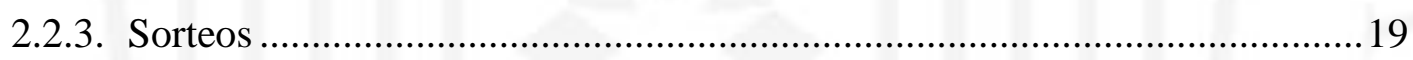

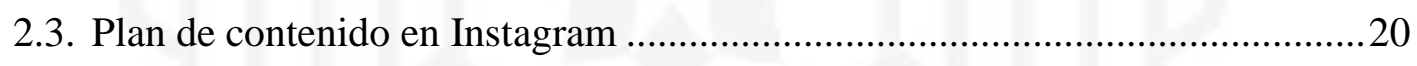

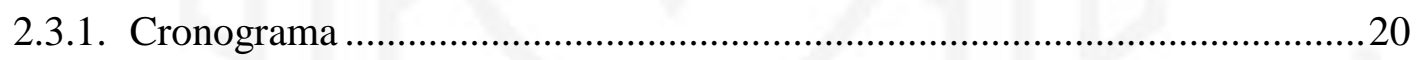

2.3.2. Formato de descripción en las publicaciones ............................................20

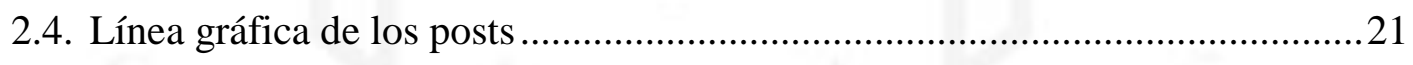

CAPÍTULO III: SUSTENTACIÓN .....................................................................................25

3.1. Validación con el público objetivo mediante entrevistas................................25

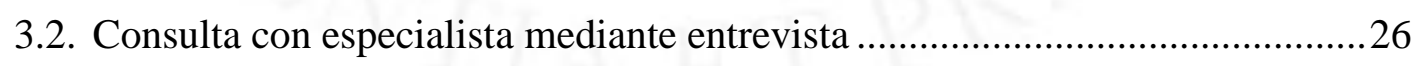

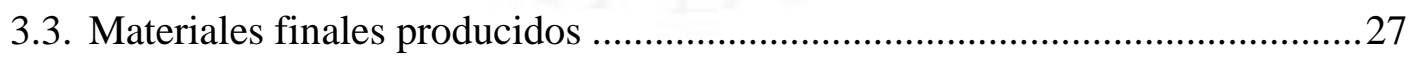

CAPÍTULO IV: LOGROS Y RESULTADOS ...........................................................30

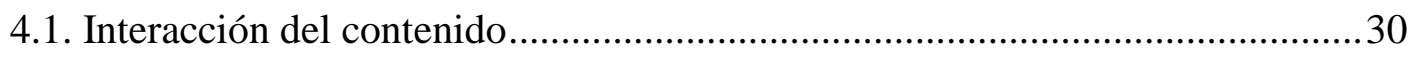

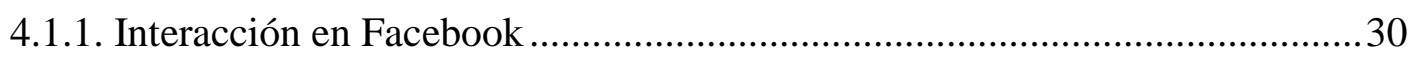




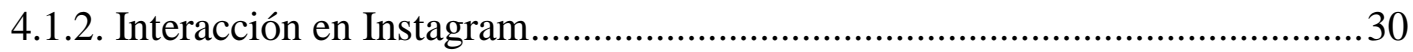

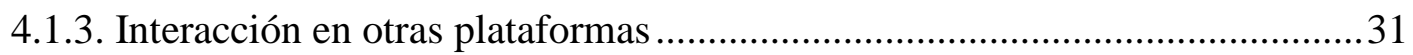

4.2. Métricas en plataformas de reproducción ....................................................... 31

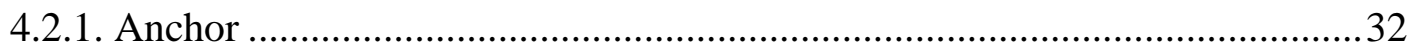

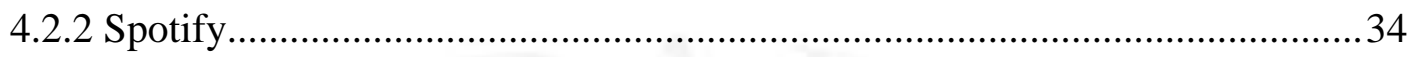

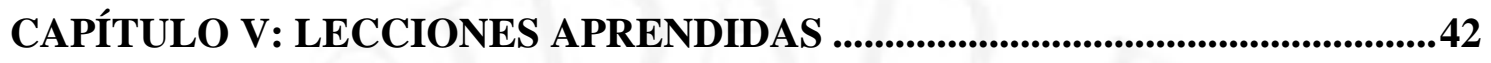

5.1. Creación del podcast Pisando Tierra .......................................................... 36

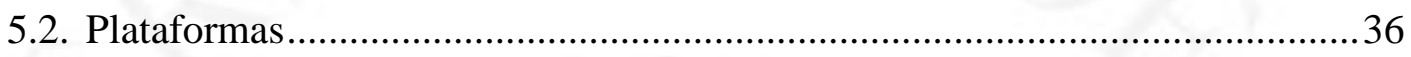

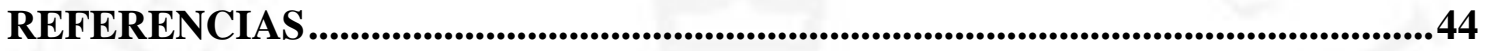




\section{RESUMEN}

El producto Pisando Tierra es un podcast que comenta temas de sostenibilidad ahondando en los diecisiete Objetivos de Desarrollo Sostenible (ODS) que impulsa la Organización de las Naciones Unidas (ONU) como parte de las metas mundiales que deberíamos alcanzar los 193 países que conforman esta organización hacia la Agenda 2030.

Realizamos este producto con la motivación de dar a conocer los ODS de manera sencilla y destacar iniciativas peruanas que actualmente aportan a ellos desde distintas áreas.

Tras entrevistas a expertos sobre el contenido publicado en el podcast Pisando Tierra, se pudo mejorar la propuesta sonora del podcast. A modo de complemento de esta información, se analizó las estadísticas obtenidas de Spotify, plataforma principal para la reproducción de los programas, y Anchor, plataforma de almacenaje de los clips de audio de cada programa del podcast.

Durante el proyecto se optó por compartir el contenido de Pisando Tierra a través de dos redes sociales, ello alineado a los intereses del público objetivo del podcast.

Palabras clave:

Podcast, Objetivos de Desarrollo Sostenible, Spotify, Social Media Management, sostenibilidad, streaming. 


\begin{abstract}
Pisando Tierra is a podcast that comments sustainability issues in order to explain the seventeen Sustainable Development Goals (SDGs) promoted by the United Nations (UN) as part of the global goals that all 193 countries that conform this organization should reach towards the 2030 Agenda.

We made this product with the motivation to raise awareness of the SDGs. In addition, we highlight peruvian initiatives that currently contribute to this global goal from different work areas, and we try to communicate all these information in a simple way.

After interviewing experts about the content published in Pisando Tierra, we improved the proposal of the podcast. For doing so, the statistics obtained from Spotify, the main platform for the reproduction of Pisando Tierra, and Anchor, an audio storage platform, were analyzed.

During the project, the content of the podcast was shared through two social networks, aligned with the interests of the project's target audience.

Keywords:

Podcast, Sustainable Development Goals, Spotify, Social Media Management, Sustainability, Streaming
\end{abstract}




\section{INTRODUCCIÓN}

Vimos en la naturaleza sonora del podcast una oportunidad para aportar al conocimiento sobre sostenibilidad y cómo se puede trabajar por los Objetivos de Desarrollo Sostenible (ODS) en distintas áreas. Por ello, nuestra motivación fue brindar información orientada a un público joven que quiera ser parte de un cambio en pro de nuestro planeta, así como compartir el triple impacto de la sostenibilidad en el medio ambiente, sociedad y economía en cada programa del podcast a través de entrevistas a representantes de instituciones privadas, emprendimientos, ONGs o personas naturales que ya realicen acciones destacables alineadas a los ODS en Perú.

El podcast fue llamado Pisando Tierra por la expresión de "pisar tierra": ser un llamado de atención para concientizar sobre la problemática actual en el planeta que vivimos.

El objetivo general del proyecto fue producir un podcast para jóvenes adultos limeños de 18 a 25 años que comunique la importancia de los 17 Objetivos de Desarrollo Sostenible propuestos por Naciones Unidas. Para ello, determinamos tres objetivos específicos: Generar contenido sonoro para limeños de 18 a 25 años que comunique de manera sencilla en los 17 ODS, establecer plataformas de distribución y streaming de capítulos y cuentas oficiales en los 17 ODS, establecer plataformas de distribución y streaming de capítulos y cuentas oficiales en redes sociales, y analizar los datos obtenidos en redes sociales y el canal de distribución de Pisando Tierra para medir el alcance del mismo.

En la primera fase del proyecto se decidió abrir solo un canal en redes sociales: Facebook. Esto por la llegada que se tenía a través de este medio con el público objetivo del proyecto. Al pasar los meses, en la segunda fase del proyecto, se implementó una segunda red social: Instagram.

En la realización de un producto comunicacional como el podcast se debe tener en cuenta los dos tipos de plataformas que existen: para distribución y almacén. En el caso de Pisando Tierra se escogió Spotify y Soundcloud, respectivamente. Sin embargo, meses después, se tuvo que migrar a Anchor por beneficio del proyecto. 


\section{CAPÍTULO I: ANTECEDENTES DEL TRABAJO}

\subsection{Importancia del podcast}

Se sabe que la llegada de la radio digital constituye el siguiente paso en la evolución del audio online, ya que existe un quiebre de la temporalidad clásica de la radio que ofrece una mayor dosis de personalización de la escucha (García-Marín y Aparici, 2018). Es en este nuevo ecosistema de la comunicación sonora que surge el podcast: una fusión de dos tecnologías: el audio digital y los motores de descarga automática de contenidos (Cebrián-Herreros, 2009).

Ahondando un poco más en la definición, Santiago Romero (2018), redactor en BBVA World comenta lo siguiente:

El 'podcast' - palabra que fusiona iPod y 'broadcast' (emisión) - es una emisión de sonido que cualquier usuario puede descargar de internet y reproducir en el dispositivo que se desee. Desde un ordenador a un reproductor portátil. Suelen tener una publicación digital periódica en serie, lista para ser consumida cuando el oyente quiera.

Hoy en día, con tantos estímulos audiovisuales, el podcast se ha convertido en una herramienta efectiva, ya que requiere solo uno de nuestros sentidos: el oído. Y, a diferencia de la radio, se puede seleccionar el contenido antes de darle play, así como pausar, adelantar o simplemente saltar un episodio. La comodidad, dinamismo y flexibilidad del podcast atrae a cada vez más usuarios. Para darnos una idea de la popularidad y auge del podcast: "En este momento, hay más de 700,000 podcasts activos en EE. UU. y más de 29 millones de episodios de podcasts" (2019).

En adición, queremos destacar que, según Bonini (2015), “el podcasting es una tecnología usada para distribuir, recibir y escuchar contenido sonoro on-demand producido por personas independientes, artistas y radio aficionados”. En ese sentido, según Sellas (2011), la producción de podcasts es muy amplia. Se pueden hallar podcasts independientes y profesionales, individuales y colectivos. de ámbito muy local y de contenidos globales. Por ello, "la oyente gana autonomía y posibilidades, por lo que (...) 
importan los contenidos. El usuario decide sobre ellos y sobre el modo y tiempo de consumo" (Ibidem).

\subsection{El podcast en el Perú}

Convoca Radio, a raíz de su segundo aniversario de creación, realizó un especial sobre el avance del podcast en el Perú. Ellos comentan que "en el Perú existen aproximadamente 50 podcasts y que la mayoría de ellos ha desarrollado el formato de charla y un público muy definido" (Velezmoro, 2019), dependiendo del contenido. Asimismo, comentan sobre su experiencia compartiendo géneros periodísticos como el reportaje, la crónica y el perfil generando contenido sonoro innovador para su audiencia a través del podcast. Mediante entrevistas este programa sobre el avance del podcast en el Perú, Anderson Ávila, creador de El Langoy ${ }^{1}$, comenta que lo que hace falta es la difusión para llegar a más audiencia. Por el lado de Hans Rothgiesser, de Nación Combi ${ }^{2}$, hablar de un mayor acceso a financiación también es un tema de interés.

Un caso de éxito del fenómeno del podcast es Radio Ambulante ${ }^{3}$, una creación del escritor peruano Daniel Alarcón. "Lo que comenzó como un nuevo proyecto para él, en 2014 logró consolidarse con el Premio Gabriel García Márquez de Periodismo en la categoría de Innovación", cuenta Sergio Sicheri de El Comercio. Actualmente, Radio Ambulante ya forma parte de las más de 900 estaciones de radio pública de los Estados Unidos en la National Public Radio (Sicheri, 2018).

Además, en el Perú, las emisoras de radio están apostando por este formato sonoro. Medios de comunicación tradicionales como RPP y La República tienen compendios de podcasts de diferentes temas, ampliando su oferta al entretenimiento, alcanzando un total de 26 y 20 posdcasts respectivamente.

\subsection{La sostenibilidad como temática de podcasts peruanos}

El concepto de sostenibilidad implica el desarrollo de un triple impacto: social, ambiental y económico. Muchas veces la sostenibilidad es confundida con la descripción de cambio climático o medio ambiente. Por dicha razón, específicamente sobre sostenibilidad,

\footnotetext{
${ }^{1}$ El Langoy es uno de los podcasts referentes del Perú estrenado en 2014. Su espacio está dedicado a la conversación sobre cultura pop y coyuntura nacional.

2 Desde 2015, Nación Combi es un espacio de diálogo sobre política, economía y actualidad peruana.

3 https://radioambulante.org/
} 
podemos encontrar algunos capítulos de podcasts, no un contenido de publicación continua. Tras búsquedas online encontramos los siguientes contenidos, que se acercan de alguna u otra manera a categorías como medio ambiente o ecología:

- Encontramos un episodio en SoundCloud del Servicio Nacional de Áreas naturales protegidas por el Estado (SERNANP) sobre el sector económico dentro de la sostenibilidad en formato podcast.

- Adicionalmente a ello, en Spotify, "La voz de Gio" comenta en torno a la maternidad sostenible y cuenta con cinco capítulos.

- "Mueve la flecha" de contenido educativo y ambiental, intenta contribuir a la gestión de los limitados recursos del planeta. Cuentan con diecisiete capítulos en Spotify.

- El podcast de Lima Compost cuenta con 11 capítulos en Spotify y se utiliza con una fuente adicional de información sobre lo que ellos realizan como empresa de compostaje.

- "Vida casi cero" comunica acciones de reciclaje, alternativas ecológicas y, en general, una filosofía Zero waste o consumo responsable. Cuenta con 6 capítulos en Spotify.

- Oceana Perú ha iniciado las publicaciones de su podcast vía Facebook. Ellos comentan la necesidad del cuidado de la fauna marina.

En cuanto a programas radiales, una investigación peruana demuestra que algunas radios comunitarias presentan interés en desarrollar temas de medio ambiente debido al incremento de fenómenos ambientales en sus localidades. En este caso, Santillan (2015) recoge información sobre "JHC" de la ciudad de Chiclayo, "Rimarinakusunchis" del distrito de Urubamba y "La Voz de la Selva" de la ciudad de Iquitos. Estas tres radios comunitarias presentan diversos bloques en los que conversan acerca de: reciclaje, reducción y reutlización; gestión ciudadana responsable con el medio ambiente; prevención de riesgos de desastres generados por el cambio climático; etc.

A diferencia de estos pocos ejemplos, a nivel mundial sí hallamos muchas cuentas dedicadas específicamente a sostenibilidad dentro de plataformas como PlayerFM, 
SoundCloud, iTunes, Spotify, iVoox, e incluso fuera de ellas, a través de páginas webs de universidades, revistas, medios de noticias, entre otros (Anexo 1).

\subsection{Análisis para la elección del público objetivo de Pisando Tierra}

Complementando la información anterior, nos parece importante destacar que la escucha de podcasts es más popular en jóvenes, con $67 \%$ del total de audiencia entre los 18 y 44 años en EE.UU. (Podcast Statistics, 2019). Y, en cuanto a data nacional, "los consumidores de audio digital peruanos han aumentado de $35 \%$ a $65 \%$ de 2015 a finales de 2018” (Cóndor, 12 de julio de 2019).

Es así como Pisando Tierra eligió como público objetivo a una parte del segmento adolescente joven y joven adulto de los rangos establecidos por Ipsos. Según esa data, dentro del perfil del adulto joven peruano de Ipsos (2018), el $85 \%$ de millennials en nuestro país es digital y un $78 \%$ usa redes sociales. Además, según Datum, $29 \%$ del total de la población peruana entre 19 y 35 años es considerada millennial. El $40 \%$ de ellos tiene o está estudiando una carrera universitaria o técnica y un $41 \%$ tiene secundaria completa (2017). Estos valores nos permitieron determinar nuestro público objetivo: jóvenes limeños entre 18 a 25 años de Lima Metropolitana con acceso a internet.

Ahora, a nivel mundial, según la Encuesta a la generación millennial 2019 de Deloitte $^{4}$, “en lo que a sus preocupaciones se refiere lidera el ranking global el cambio climático, la protección del medioambiente y los desastres naturales".

\subsection{Los Objetivos de Desarrollo Sostenible en el contexto peruano}

La Organización de las Naciones Unidas (ONU) realizó un reporte 2019 sobre el Desarrollo Sostenible de los 193 países que la conforman y se comprometieron a alcanzar metas hacia el año 2030.

\footnotetext{
${ }^{4}$ Cabe resaltar que para la elaboración de dicho informe, se ha recogido la opinión de más de 13.400 millennials en 42 países.
} 
En la presente gráfica se observa el nivel de avance de Perú en materia de los ODS:

\section{PERU}

Latin America and the Caribbean

\section{$\checkmark$ OVERALL PERFORMANCE}

Index score

Regional average score
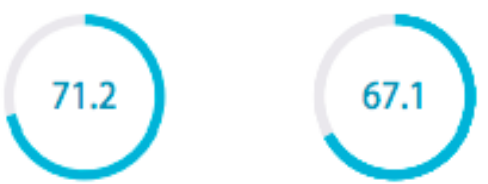

SDG Global rank 51 (OF 162)

\section{SPILLOVER INDEX}

100 (best) to 0 (worst)
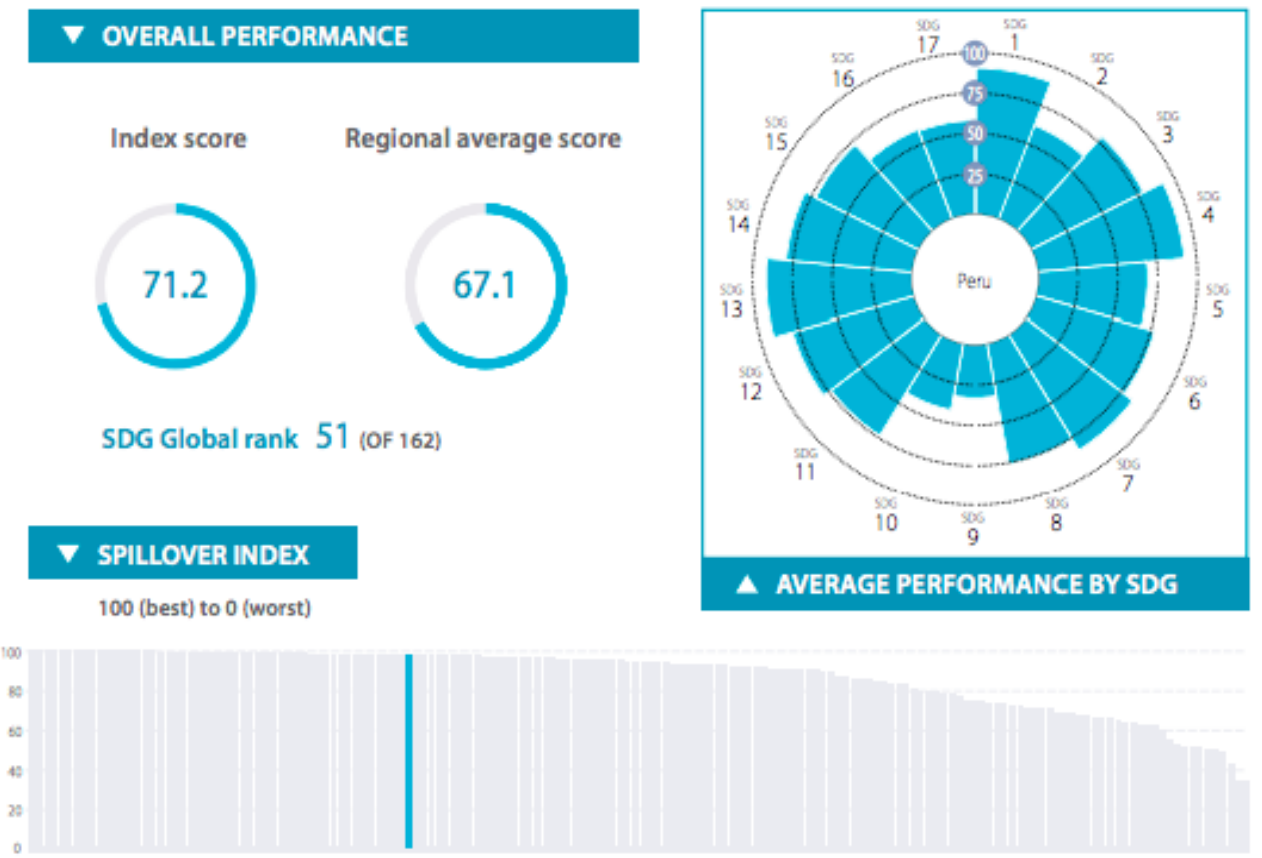

V CURRENT ASSESSMENT - SDG DASHBOARD

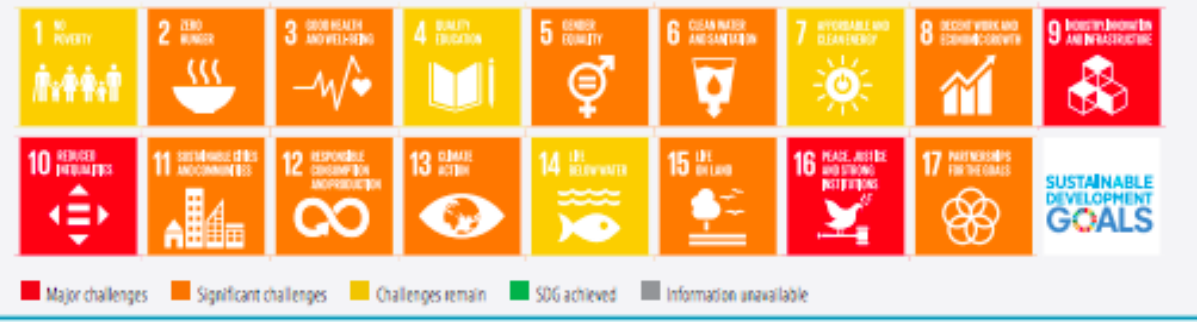

$\boldsymbol{\nabla}$ SDG TRENDS

\begin{tabular}{|c|c|c|c|c|c|c|c|c|}
\hline 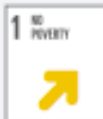 & $\begin{array}{c}2 \text { 푬 } \\
y\end{array}$ & 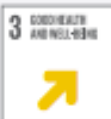 & 4 & 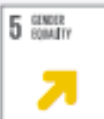 & 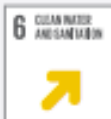 & 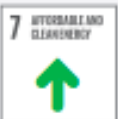 & 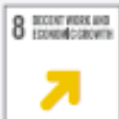 & 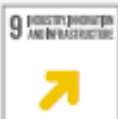 \\
\hline 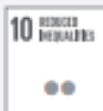 & 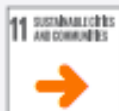 & 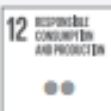 & 13 & 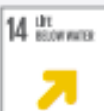 & 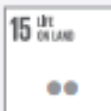 & 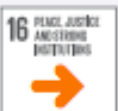 & 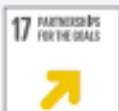 & \\
\hline
\end{tabular}

Fuente: Naciones Unidas 
La comunicación de los Objetivos de Desarrollo Sostenible (ODS) presenta oportunidades de mejora, ya que para lograr una consecución de las diversas metas en necesario, en primer lugar, que nuestra población conozca al respecto.

Realizamos una investigación sobre los aportes públicos y privados sobre organizaciones que comunican el significado de los ODS, comparten iniciativas externas que se hayan alineado a estos objetivos o que incluso comparten producción sonora o audiovisual respecto a esta temática:

\begin{tabular}{|c|c|c|c|}
\hline Nivel / Categorías & $\begin{array}{l}\text { Organización } \\
\text { privada }\end{array}$ & Institución pública & $\begin{array}{c}\text { Organismo internacional } \\
\text { /Movimiento social }\end{array}$ \\
\hline $\begin{array}{c}\text { Comunica los ODS } \\
\text { activamente en al menos una } \\
\text { plataforma digital }\end{array}$ & $\begin{array}{l}\text { Agenda } 2030 \text { Perú, } \\
\text { Avanza Sostenible }\end{array}$ & INEI & $\begin{array}{l}\text { Pacto Global Perú, } \\
\text { Directorio Sustentable } \\
\text { latinoamericano }\end{array}$ \\
\hline $\begin{array}{l}\text { Además comparte iniciativas } \\
\text { fuera de su jurisdicción }\end{array}$ & $\begin{array}{l}\text { Perú 2021, Kunan, } \\
\text { Libélula, Nexos+1 }\end{array}$ & $\begin{array}{l}\text { Ministerio } \\
\text { Ambiente }\end{array}$ & $\begin{array}{l}\text { The Millennials } \\
\text { Movement, Banco } \\
\text { Interamericano } \\
\text { Desarrollo }\end{array}$ \\
\hline $\begin{array}{l}\text { Incluso cuenta con } \\
\text { producción sonora o } \\
\text { audiovisual }\end{array}$ & & & $\begin{array}{l}\text { Naciones Unidas (Perú } \\
\text { por los ODS, PNUD, } \\
\text { FAO, UN Climate), } \\
\text { Centro de ODS para } \\
\text { América Latina }\end{array}$ \\
\hline
\end{tabular}

Fuente: Elaboración propia

Hemos dividido los aportes en tres niveles y categorías respectivamente, debido a que buscamos que esta información nos proporcione un benchmark adecuado con el cual podamos comparar la producción de Pisando Tierra. 
En ese sentido, en un nivel básico estamos posicionando a las organizaciones que comunican los Objetivos de Desarrollo Sostenible (ODS) activamente en al menos una plataforma digital. En un nivel intermedio se encuentran las organizaciones que además de la afirmación anterior, comparten iniciativas fuera de su jurisdicción. Es decir, que están genuinamente comprometidos con el conocimiento de más acciones alineadas a los ODS aun así no estén involucrados en su realización. Finalmente, el nivel avanzado comprende a las organizaciones que, además de los destacado anteriormente, cuentan con producción sonora o audiovisual que permita comunicar los ODS.

Nivel "Comunica los ODS activamente en al menos una plataforma digital":

- Organizaciones privadas como Agenda 2030 Perú o Avanza Sostenible comunican los Objetivos de Desarrollo Sostenible a través de sus redes sociales debido a su core business: asesoría corporativa en materia de sostenibilidad.

- La única institución pública que comunica el avance de los ODS en su web es el Instituto Nacional de Estadística e Informática (INEI), ya que cuentan con un sistema de monitoreo y seguimiento de los indicadores de los Objetivos de Desarrollo Sostenible. Si bien esta herramienta permite encontrar cierta información, el INEI no ha realizado la comunicación debida para que más personas puedan enterarse de cómo acceder a esta información pública, libre y digital.

- En cuanto a Organismos internacionales, el Pacto Mundial, la iniciativa más grande de sostenibilidad corporativa, publica a través de sus redes sociales el significado de algunos ODS, además, gracias a sus 10 principios incentivan a las empresas a apoyar y promulgar, dentro de su esfera de influencia, un conjunto de valores fundamentales en las áreas de derechos humanos, normas laborales, medio ambiente y anti-corrupción. Por el lado de los movimientos sociales, el Directorio Sustentable latinoamericano comparte información en sus redes sociales sobre los ODS que empresas miembros del directorio están llevando a cabo.

En ambos casos, publicar sobre los ODS de manera informativa es solo un nivel básico, según nuestras consideraciones. 
Nivel “Además comparte iniciativas fuera de su jurisdicción”:

- Organizaciones privadas como Perú 2021, Kunan, Libélula o Nexos+1 buscan que más personas conozcan sobre los ODS ya que sus modelos de negocio implican la entrega de distintivos a empresas, start ups u ONGs, así como realización de eventos, foros o ponencias que buscan brindar conocimiento especializado sobre sostenibilidad, medio ambiente, y las metas que debemos cumplir para la Agenda 2030.

- El Ministerio del Ambiente, un actor clave para la comunicación y consecución de los Objetivos de Desarrollo Sostenible logra compartir investigaciones exitosas que suplen, por ejemplo, al plástico de un solo uso; mantiene alianzas con entidades clave que aportan en la reducción de huella de carbono, consumo responsable y más metas de los ODS. Aun así, el MINAM no logra alcanzar un nivel avanzando debido a que comunica sobre los Objetivos a través de informes e incluso el Sistema Nacional de Información Ambiental (SINIA) no cuenta con producción sonora o audiovisual orientada a algún público en el que explique de manera detallada cada ODS.

- El Banco Interamericano de Desarrollo (BID) constantemente da a conocer proyectos que aportan a uno o más Objetivos de Desarrollo Sostenible, de manera que más personas pueden notar el avance en materia de sostenibilidad y desarrollo. Si bien ellos comunican esta información a través de videos en sus redes sociales y de artículos en su web. Un movimiento social integrado por jóvenes es The Millennials Movement y ellos, al igual que el BID, realizan muchísimas acciones para dar a conocer los Objetivos a más chicos a través de eventos, videos, convocatorias en redes, etc. Aún así, ambos casos no alcanzan el nivel avanzado debido ya que les hace falta producción sonora especializada en explicar los ODS.

Nivel "Incluso cuenta con producción sonora o audiovisual":

- Dos organizaciones internacionales que realizan muchos aspectos mencionados anteriormente y además cuentan con producción de podcast son la Organización 
para las Naciones Unidas (ONU) y el Centro de ODS para América Latina (CODS).

Tras este estudio, decidimos comparar la oferta de Pisando Tierra con las organizaciones internacionales que cuentan con podcasts y toman los Objetivos de Desarrollo Sostenible como temática para su producción.

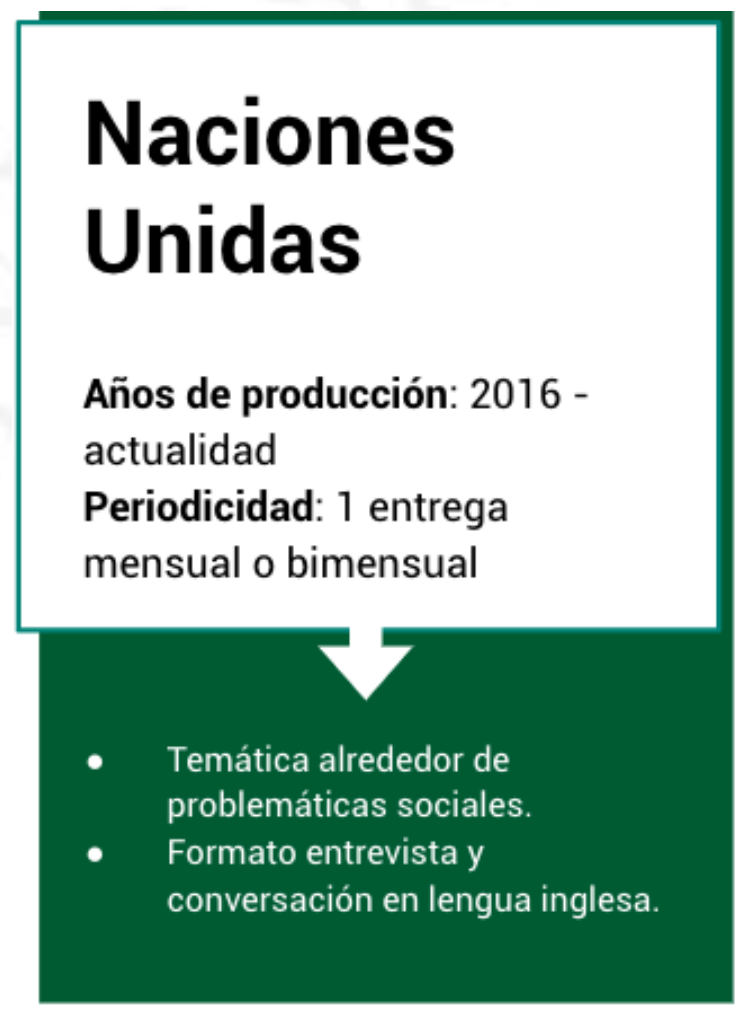

\section{Centro de ODS para América Latina}

Años de producción: 2018 actualidad

Periodicidad: 2 entregas al mes

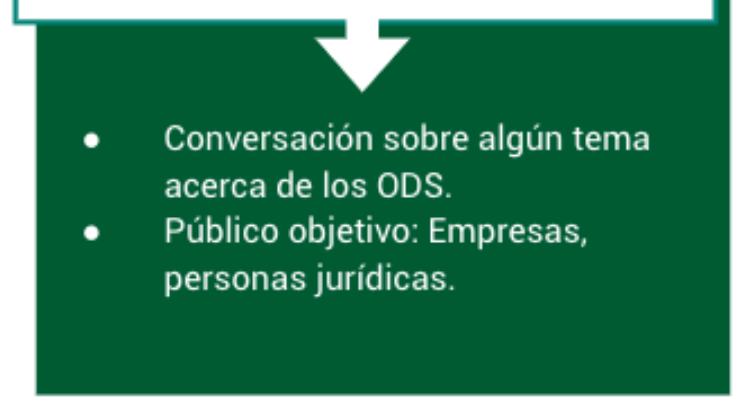

Fuente: Elaboración propia

Al realizar el benchmark encontramos aspectos positivos y negativos en común que compartimos seguidamente:

- Aspectos positivos

- Cuentan con una careta inicial, lo que se percibe como un detalle de profesionalismo e interés en la atmósfera de su producto sonoro.

- La claridad vocal de los locutores permite el entendimiento de la información brindada. 
- Sus fuentes de información son verificadas, lo cual aporta de contenido de calidad para los oyentes.

- La plataforma de publicación de sus podcasts es amigable. Ambas organizaciones utilizan SoundCloud, por lo que las funciones son actuales y pueden hacer uso de hashtags, recibir comentarios, aceptar suscriptores, etc.

- Oportunidades de mejora

- La utilización de lenguaje especializado no permite que un usuario con conocimientos básicos sobre el tema comprenda en su totalidad el tema de conversación.

- En diversos programas, la conversación prolongada (programas de 20 min. en adelante), por lo que la atención del oyente puede decaer e incluso abandonar la escucha.

Tomando en cuenta todo lo anterior, decidimos enmarcar nuestro proyecto en torno a los Objetivos de Desarrollo Sostenible (ODS), los cuales proporcionan un marco de referencia para comunicar progresos en materia económica, social y ambiental en un idioma reconocible en todo el mundo. Los ODS se gestaron en la Conferencia de las Naciones Unidas sobre el Desarrollo Sostenible, celebrada en Río de Janeiro en 2012. El propósito era crear un conjunto de objetivos mundiales relacionados con los desafíos ambientales, políticos y económicos con que se enfrenta nuestro mundo. Este conjunto de diecisiete objetivos esboza el camino para lograr un mundo más próspero y sostenible para el año 2030.

Es así como, a través de los ODS, proponemos temáticas en torno a uno o más de un objetivo por programa, explicando al oyente de manera sencilla cómo se vienen trabajando diversos proyectos a nivel mundial y también a nivel nacional, con un entrevistado peruano (empresario, representante de una institución pública u ONG, activista o inmerso en temas de sostenibilidad, ecología o medio ambiente). 


\section{CAPÍTULO II: REALIZACIÓN}

El podcast Pisando Tierra comenzó como un proyecto que pretendía realizar cinco episodios que contemplen los ODS como eje, teniendo en cuenta a la sostenibilidad, ecología y medio ambiente como temas principales. Luego, la idea evolucionó de hablar únicamente de esos cinco tópicos a una búsqueda por generar contenido que abarque todos los ODS que sea posible. En cada programa se explican las acciones de uno de los diecisiete ODS (o más de uno si es que el tema lo permite), para lo cual se ha entrevistado a diversos especialistas con la finalidad de ampliar el contenido; además, se incitó al público a participar del podcast a través de las publicaciones en redes sociales.

Cada episodio cuenta con un guion que, en un principio, tenía como finalidad orientar la conversación de todo el programa a nivel de contenido, música, ambientes y efectos de sonido (Anexo 2). Tras la primera validación con el público objetivo, se comentó que la conversación no era real, por ello, se comenzó a usar un guion de referencia. Esto permite mayor libertad y un tono más cercano al oyente.

En cuanto al contenido teórico del guion de cada programa, se estructuró cada capítulo del podcast tomando en cuenta la importancia de explicar de manera resumida y atractiva cada Objetivo de Desarrollo Sostenible (ODS) abordado. Los aspectos que se consideran para esta explicación son: definición de términos, datos numéricos importantes del problema que se quiere resolver, ejemplo de cómo se viene trabajando a nivel internacional y una entrevista a un ejecutor de este ODS en Perú.

En total se trataron los siguientes ODS: 


\section{OBJETIVOS SODESTARROLLO}

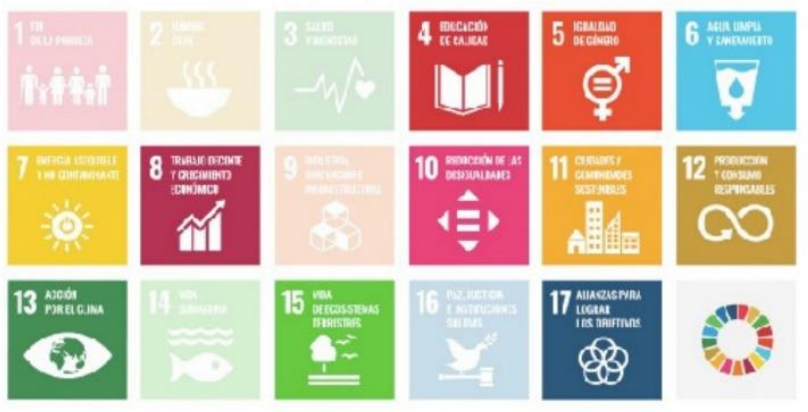

\section{iA la fecha hemos comunicado once ODS a través de nuestro podcast!}

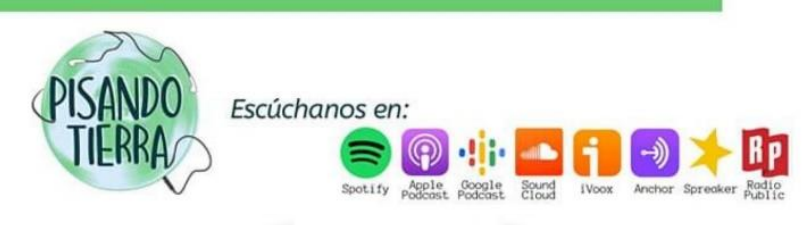

Fuente: Elaboración propia

A través de conceptos y ejemplos sencillos se buscó comentar a qué se refiere el ODS tratado, cómo vamos avanzando en esa materia a nivel nacional y complementar esa información con una entrevista entre 5 a 10 minutos. Es gracias a esta última parte que se puede aterrizar aún más en iniciativas concretas que se pueden realizar y en la importancia de seguir avanzando en torno al desarrollo sostenible.

Tras 6 meses de producción, alcanzamos un total de 12 episodios y 9 entrevistas. Se optó por publicar, además de los programas, las entrevistas a especialistas de manera individual para que el público pueda recepcionar la información en su totalidad sin ediciones y de corrido en la misma plataforma. Ello permite que, en caso se quiera consultar algún detalle en específico comentado por el especialista invitado, se pueda acceder a este clip ágilmente.

En cuanto a la elección de los ODS, se tuvo una lista tentativa inicial que incluía a los entrevistados por programa, pero esta cambió y por ende los entrevistados también (Anexo 3). Consideramos en dicha lista inicial solo algunos objetivos debido a que su explicación era más sencilla para el oyente, conocíamos a expertos dispuestos a ayudarnos con las entrevistas y porque teníamos fuentes suficientes para dar a conocer datos actualizados sobre el tema. 
A fin de contar con información relevante para el programa, seguimos atentamente eventos, publicaciones y otros a través de redes sociales como Facebook, Twitter y LinkedIn. Algunas de las instituciones que comparten contenido diario sobre temas de sostenibilidad son: Naciones Unidas, el Ministerio del Ambiente de Perú, el Programa de las Naciones Unidas para el Desarrollo, el Banco Interamericano de Desarrollo, Libélula, Hubbub, y otras personalidades o profesionales. Asimismo, seguir hashtags como \#SDG, \#ODS, \#DesarrolloSostenible, \#podcasting, \#educación, \#medioambiente, \#ConsumoResponsable, \#Reciclaje, y otros más, permite encontrar más data relevante para la temática de nuestro podcast (Anexo 4).

Además del contenido, se tuvo que tomar decisiones sobre la plataforma de almacenamiento, la cual se cambió de SoundCloud a Anchor como se explicará más adelante, las redes sociales a usar y la plataforma de distribución de audio que sería nuestro principal canal. Para comenzar con la realización del proyecto debíamos formar una identidad gráfica y tono de comunicación para el podcast:

\subsection{Manual de marca de Pisando Tierra}

Para empezar con las acciones planteadas, se tenía que crear lineamientos gráficos y de comunicación que se debían seguir a lo largo del proyecto. Primero, se formuló un nombre acorde al objetivo principal. El nombre elegido fue Pisando Tierra por el eufemismo de "pisar tierra" y ser consciente de los problemas socioambientales presentes. El logo es referente al formato del podcast (audífonos) y al nombre. Para lograr el resultado final, se realizaron diversos bosquejos con ideas clave iniciales representativas a la temática del programa (Anexo 5).

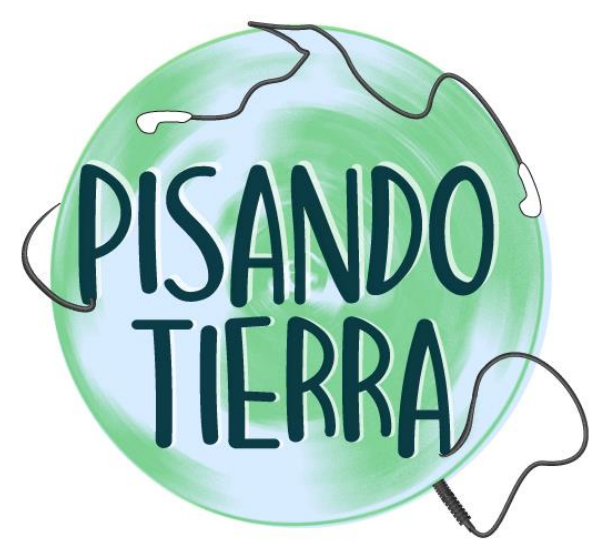


El logo contiene elementos principales como los audífonos, los colores del planeta Tierra y de fondo que se asemejan a un disco en movimiento. Los audífonos y el disco hacen referencia al formato de audio utilizado para el proyecto. Además, los primeros están conectados al planeta, haciendo un llamado a los usuarios de Pisando Tierra a escuchar al planeta y las necesidades del mismo.

En el tiempo establecido de duración del proyecto, se manejó un primer formato gráfico en Facebook, el cual se modificó al comenzar actividad en Instagram. El primero consistía en una imagen libre de derechos de autor que hacía referencia al tema del episodio, el uso de la tipografía HelloMozza!, presencia de las plataformas de distribución de podcasts que usábamos y el logo en la esquina inferior derecha de la imagen.

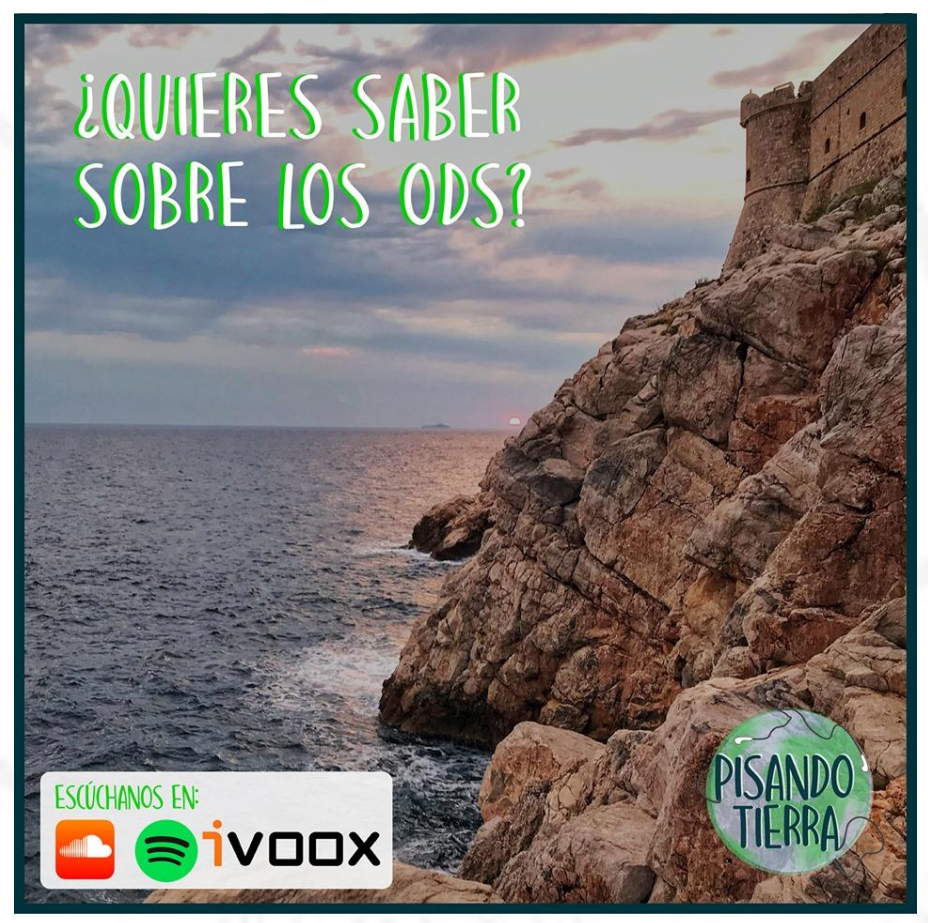

En los últimos meses, al acceder a Instagram, la línea gráfica fue cambiada de tipografía y formato de diseño. Se usó la fuente Abeezee y estas podían ser azules, verdes o blancas dependiendo de la imagen utilizada en la publicación. De este formato existen tres diseños, las cuales presentan el logo del podcast, las plataformas de distribución utilizadas y la misma tipografía. Sin embargo, se modifica el tamaño de la foto utilizada y la distribución del texto según la función de la imagen como se explicará más adelante. 


\subsection{Plan de contenido de Facebook}

Durante los tres primeros meses del proyecto se decidió usar solo a la plataforma Facebook para la publicación de contenido en redes sociales debido a su popularidad en el público objetivo que se manejó en ese momento (jóvenes de 16 a 18 años). En cuanto a la foto de perfil de nuestra página en Facebook, se decidió colocar el logo de Pisando Tierra y se tuvo una primera semana de publicaciones generales sobre los ODS y recomendaciones de eventos para generar movimiento en la red antes de subir el primer programa del podcast: Introducción a la Sostenibilidad.

Se realizó un cronograma de publicaciones para definir el momento y la temática de cada post por realizar; de este modo, fue importante realizar una parrilla de contenido (Anexo 6).

El hecho de compartir eventos o información de los Ministerios del Perú y ONGs según conveniencia fue un factor clave para el movimiento en redes sociales. El contenido compartido tenía como objetivo el otorgar mayor conocimiento a los oyentes y usuarios de Facebook sobre sostenibilidad de manera complementaria al contenido brindando por nosotras a través del podcast.

A continuación, se explicará con mayor detalle estos puntos:

\subsubsection{Cronograma}

Decidimos que el ODS que predomine en el programa de la semana también se pueda comunicar en la página a través de elementos multimedia como imágenes, videos, infografías o audios. Las publicaciones se realizaron en primera instancia los lunes, miércoles y viernes, siendo este último el día de publicación del nuevo episodio.

\subsubsection{Formato de descripción en las publicaciones}

Mediante la descripción textual de las publicaciones de los lunes y miércoles se buscó interacción con el usuario y generar intriga en ellos con respecto al nuevo episodio. Además, se colocaron los links de las plataformas utilizadas, los cuales dirigen al perfil del podcast. En cuanto al texto de descripción de las publicaciones de los viernes, se 
etiquetó a la organización entrevistada para generar mayor alcance y permitir que el entrevistado comparta la publicación. También se colocó el link principal, el cual enlaza al perfil de Spotify de Pisando Tierra Podcast.

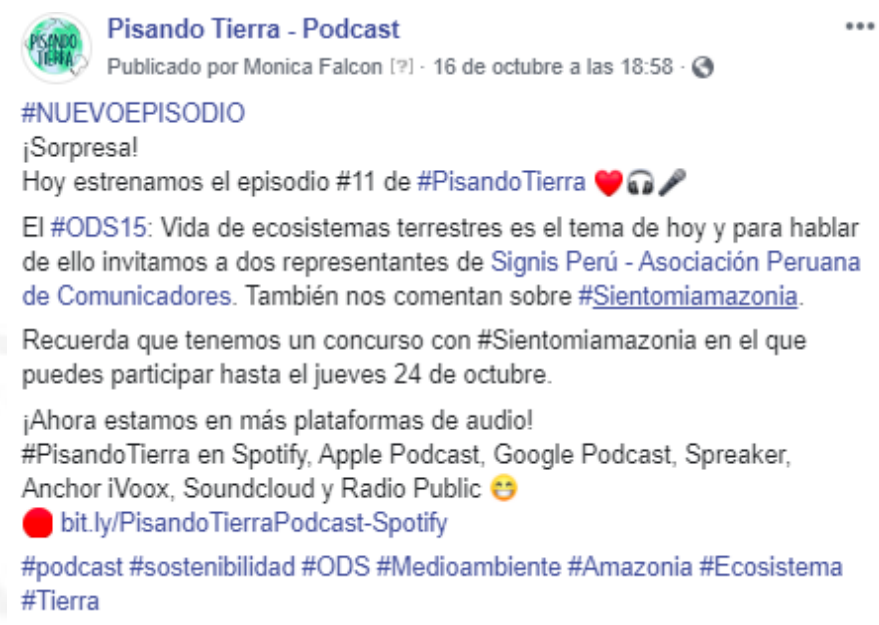

\subsubsection{Sorteos}

Dos indicadores para formar una comunidad de escuchas en el podcast fue el número de personas que seguían la página y las interacciones que se lograban en las publicaciones. Por dicha razón, se realizaron tres concursos con premios acorde a los ODS que se estaban hablando en el momento dentro del podcast. En el primero, sorteamos objetos que no contaminan más el medio ambiente, ya que no se usaba plástico sino metal o bambú. En el segundo sorteo se incluyó un bolso de tocuyo y el logo de la empresa Evea en caucho natural, además de un polo 100\% algodón de la marca Esprit. Ambos tuvieron participación del público compartiendo algún comentario sobre el podcast o respondiendo alguna pregunta dejada anteriormente. El último sorteo era para tres ganadores distintos con el fin de incentivar el uso de elementos ecoamigables, alimentación saludable y una acción por el clima a través del cuidado de una planta.

Se consiguió resultados favorables como participación en las publicaciones y el aumento de la cantidad de interacciones con los posts en un $1266 \%$ con respecto a las publicaciones anteriores con resultados orgánicos (Anexo 7). 


\subsection{Plan de contenido en Instagram}

A los meses de haber creado nuestra página oficial en Facebook, se decidió acceder a mayor público desde una cuenta en la red social Instagram. Se hizo uso de hashtags, los cuales fueron elegidos con un previo análisis de la popularidad y la cantidad de veces que se emplean al día en distintas publicaciones. De igual forma, se etiquetaba a las organizaciones que mencionamos en el episodio del podcast y se rebotaba el contenido en las historias de Instagram, una función que permite compartir contenido de manera rápida, con duración de un minuto en pantalla y de 24 horas de disponibilidad antes que desaparezca del perfil.

Se colocó el logo como foto de perfil y se realizó un par de publicaciones explicando de qué trataba el podcast y mencionando dónde nos pueden escuchar. Esto con la razón de publicar el nuevo episodio teniendo un público base.

Todas las interacciones de Instagram han recibido atención de forma orgánica, a excepción del último sorteo, el cual se explicará más adelante (líneas abajo en el punto 2.3.4). Al igual que con Facebook, realizamos un cronograma para la difusión del contenido, integrándose a la plantilla que ya se tenía para este fin. Por último, el perfil fue compartido por páginas de sostenibilidad como Siento mi Amazonía o qarma.pe, Recíclame, entre otros.

\subsubsection{Cronograma}

Al comienzo, se decidió publicar solo martes y jueves, a diferencia de Facebook que se publicaba solo lunes, miércoles y viernes. Sin embargo, se terminó publicando, prácticamente, todos los días en ambas plataformas por el alcance obtenido. Se usó una hora promedio, 12 del mediodía, en las primeras publicaciones para poder acceder a la métrica real sobre el momento de mayor alcance en el día. Al obtenerla, se publicó según dicha hora.

\subsubsection{Formato de descripción en las publicaciones}

El texto escrito para Instagram varía en cantidad de etiquetas, ya que se utilizan aquellas que tienen más seguidores o las que son más usadas para llegar a más usuarios. En cuanto al contenido es similar al texto de Facebook, pero solo se menciona las plataformas en 
las que está presente el podcast, mas no colocamos los enlaces de atajo hacia el nuevo episodio o nota con información por falta de funcionalidad en la red.

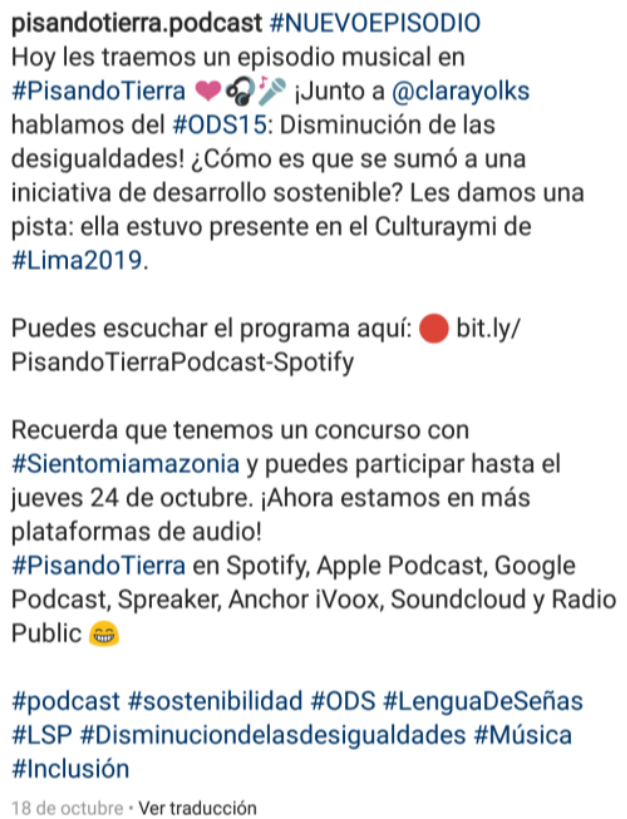

\subsection{Línea gráfica de los posts}

Las publicaciones de Instagram y Facebook de Pisando Tierra se resumen en tres formatos de diseño que comparten elementos y colores, pero son usados dependiendo del contenido por compartir:

- Gráfica para el estreno de episodios o entrevistas:

Predomina la imagen por sobre el texto, el cual se resume a anunciar el ODS tratado en el episodio y un pequeño mensaje. 


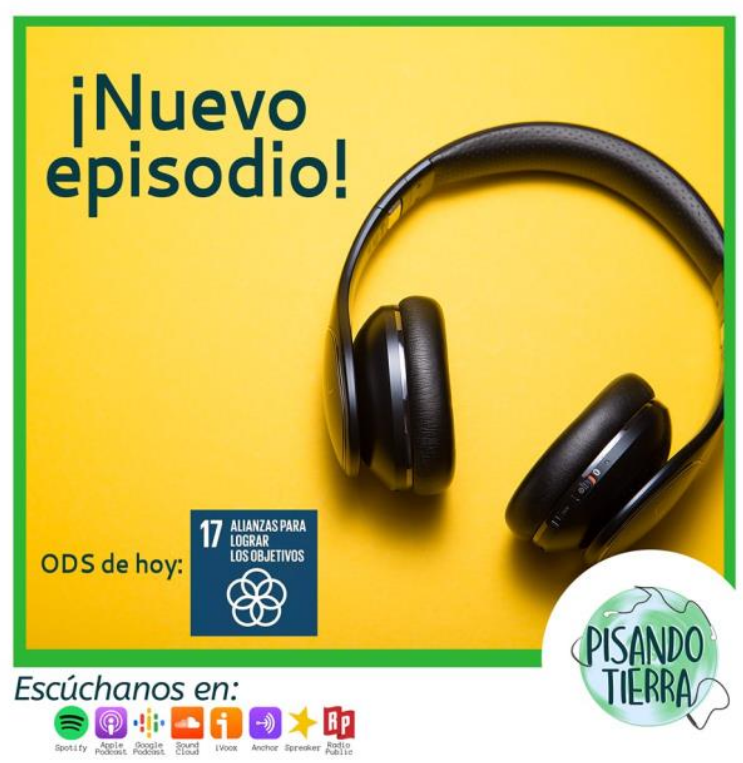

- Gráficas de mantenimiento:

El diseño busca llamar la atención del usuario y lograr una acción de su parte. Se busca armonía entre la imagen y el texto, sin tener un solo aspecto predominante.

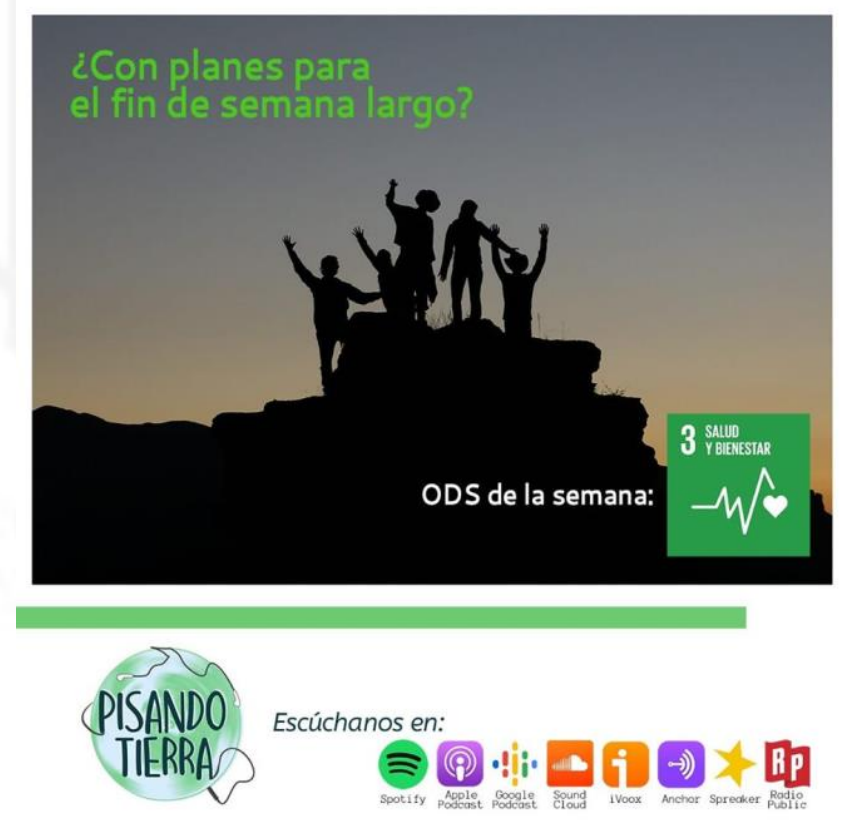


- Gráfica para complementar información:

En este diseño predomina el texto para poder complementar con información relevante al ODS del cual se esté hablando por la semana.

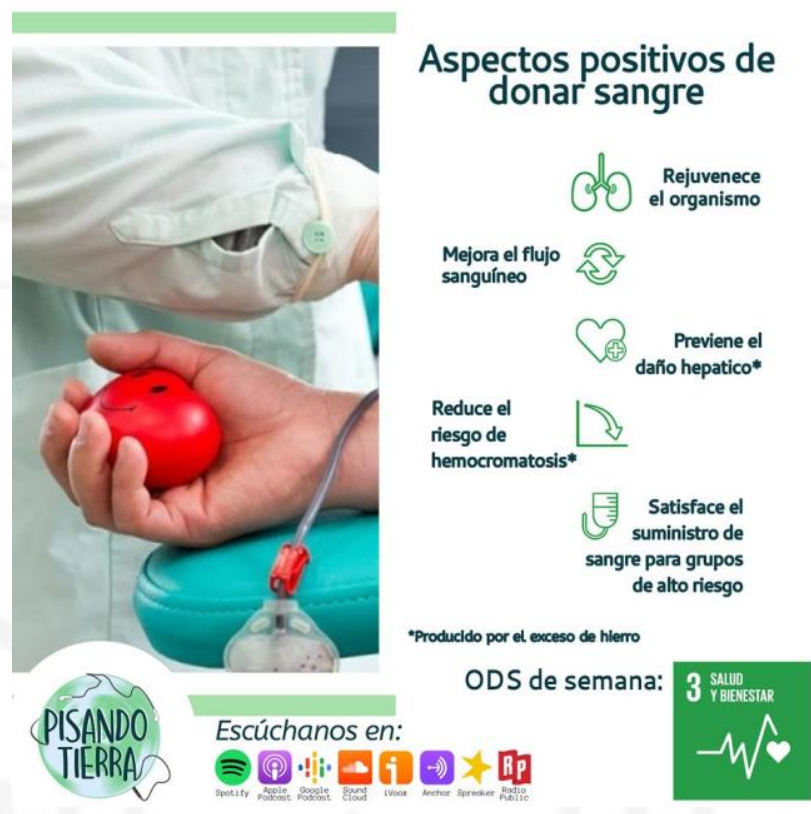

Se utilizaron los mismos elementos en los tres formatos de diseño para las publicaciones en Facebook e Instagram de Pisando Tierra. Se puede observar:

- Logo:

El logo del podcast está presente en la esquina derecha inferior para que se pueda visualizar fácilmente por el recorrido de lectura del usuario.

- Plataformas donde está el podcast: Nos pareció importante poner en la imagen las plataformas donde se cuelgan los programas. En la publicación se cuelga el link principal de distribución, Spotify.

- $\quad$ Texto (fuente, tono de comunicación) La fuente escogida es Abeezee con frases cortas que se refieran al por qué de la gráfica. Ej. “¡Nuevo episodio!”

- Imagen de fondo y marco

Se escoge una imagen libre de derechos de autor según el ODS hablado en el programa de esa semana para reforzar visualmente el tema por hablar.

- ODS desarrollado en el episodio de la semana 


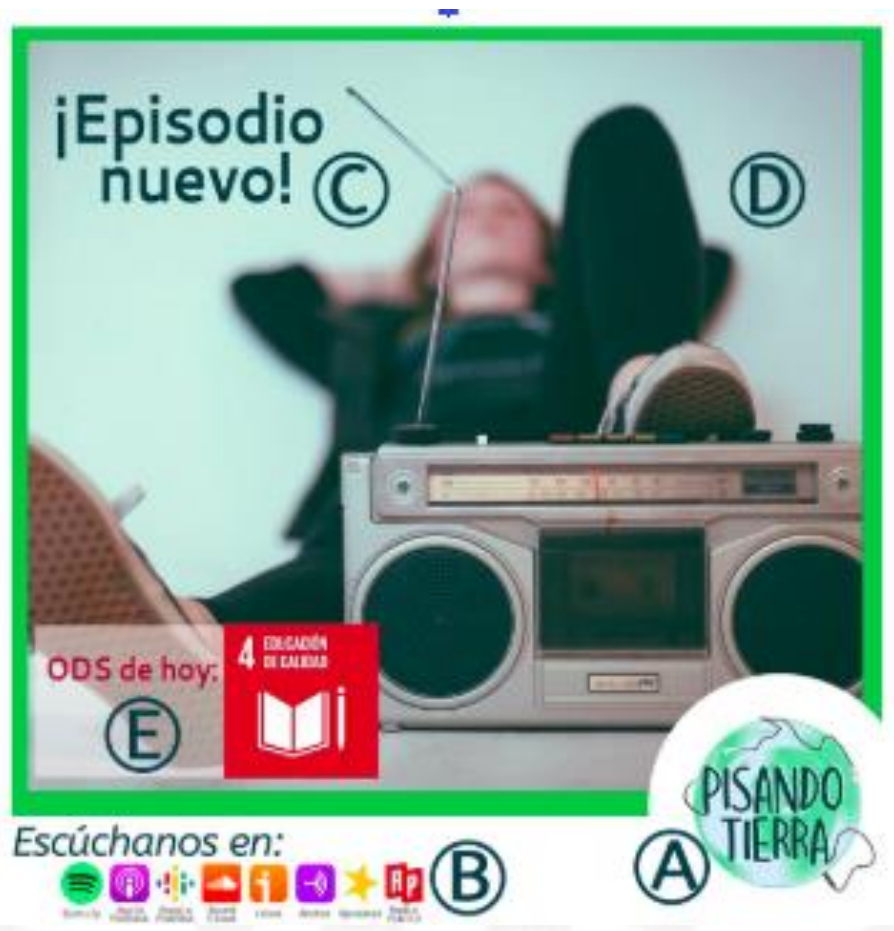




\section{CAPÍTULO III: SUSTENTACIÓN}

“En el Perú, más de 6 millones de personas escuchan audio digital. El 41\% de internautas paga algún servicio de música online y $85 \%$ realiza una escucha solitaria. Del total, el 20\% usa podcast" (Cóndor, 12 de julio de 2019).

Tomando en cuenta esta data, y las métricas obtenidas durante los meses de producción de contenido, se considera que el formato elegido presenta gran potencial de despegue y alcance ante un público peruano de 18 a 25 años. Además de ello, la temática resulta atractiva en el contexto actual debido a que los millennials demuestran genuino interés en temas de cuidado medio ambiental.

Según la información de Podcast Statistics (2019), un oyente norteamericano pasa 30 minutos al día escuchando podcasts. Teniendo en consideración que el promedio de duración de un programa de Pisando Tierra es de 10 minutos, realizamos validación con el público objetivo mediante entrevistas en las que detallaron lo siguiente.

\subsection{Validación con el público objetivo mediante entrevistas}

- Alejandra T., Responsable de Sostenibilidad en Delosi S.A. (27 años)

"Me parece que el contenido es importantísimo para difundir la importancia de los ODS en jóvenes peruanos. Durante el programa Majo y Mónica demuestran dominar los temas y elegir de manera acertada al invitado que comentar más sobre sus acciones ligados al tema del programa”.

- Ana-Lucía M., Asistente de Producción en Fade Out - Diseño y Mezcla de Sonido. (23 años)

"He aprendido más sobre los ODS gracias a Pisando Tierra. Me encanta que existan iniciativas como esta que provienen de mi misma Facultad. Creo que la calidad sonora también aporta en el podcast, ya que las entrevistas y el programa cuentan con buena definición. Además, llegar a Spotify les ha permitido ampliar su alcance". 
- Óscar R., Asistente de Calidad en Oretrans. (24 años)

"Como Egresado de Ingeniería ambiental, me es muy grato escuchar en palabras simples la explicación de algo tan importante como el ODS 12, el 5 o el 13. Lo mejor es que no me toma mucho tiempo escuchar el programa y puedo acceder a los capítulos desde la aplicación de SoundCloud en mi celular. Además, este podcast demuestra que no se necesita una ayuda visual para entender temas de medio ambiente y sociedad".

- Daniel M., Estudiante de Comunicación en USMP. (19 años)

"Escucho Pisando Tierra porque me interesa mucho aprender más sobre temas de sostenibilidad. Creo que escuchar a especialistas en diversos temas me ofrece un panorama positivo sobre los cambios que se vienen para nuestra sociedad. Me gustaría que sean más activos en otras redes sociales, pero de todas maneras creo que Facebook es un buen comienzo".

\subsection{Consulta con especialista mediante entrevista}

José Ocampo, On demand manager en RPP. Encargado de Podcasts en emisiones y grabaciones.

En cuanto a las plataformas donde comparten Pisando Tierra: lo mejor sería que amplíen la difusión del podcast con Instagram y Twitter. Esto porque el podcast es un producto de redes sociales, así que mientras estén en más redes, mejor. Además, tanto en Instagram como en Twitter el uso de hashtags está mejor empleado y eso puede redirigir bastante bien. En Twitter deben ver qué hay de tendencia y analizar si les puede servir o no, en Instagram buscar hashtags que la gente esté usando.

Los últimos episodios tienen un contenido mucho más selecto que antes. Tal vez se le puede poner más ganas a la edición que en un comienzo tenía efectos muy bien definidos. En algunos momentos la entrevista parece un comercial del producto (contenido auspiciado) lo cual puede jugar a favor o en contra. Por otro lado, existe buena distribución de contenido en el guion de cada episodio, solo se debe afinar pequeños detalles. Creo que se debe dar una razón al usuario de querer seguir escuchando. Un 
último detalle que es importante mencionar es que las locutoras sí me generan identificación.

Edward Perales, docente de pregrado en la carrera de Comunicación. Experto en generación de contenidos, producción y transmisión web.

Me gusta el proyecto. He tenido la oportunidad de escuchar los episodios desde la primera publicación hasta los del mes de setiembre. Me gustaría que la elaboración del guion tenga más espontaneidad. Aun así, celebró la temática y realización en sí.

\subsection{Materiales finales producidos}

La producción sonora del podcast se realizó en cabinas de audio semiprofesionales.

En los primeros seis meses del proyecto se empleó SoundCloud como la plataforma de almacén para los audios pero al tener limitaciones por el tiempo máximo de audios que se podía almacenar de forma gratuita se decidió migrar hacia Anchor. Ambas plataformas otorgan un $\operatorname{RSS}^{5}$ al autor del contenido, este código permite actualizar automáticamente en todas las plataformas donde se haya registrado el audio en cuestión.

A continuación se enumeran los episodios difundidos y sus enlaces correspondientes:

- \#PisandoTierra - Programa 1: Introducción a la Sostenibilidad

O Spotify: https://open.spotify.com/episode/6Fr4u23obdUBjDtYR96IS6

- \#PisandoTierra - Entrevista/Programa 1 - Rosa Bonilla

O Spotify: https://open.spotify.com/episode/0Wz0Rz98qiSaSJLoZfBi1u

- \#PisandoTierra - Programa 2: Energía renovable - ODS 7

O Spotify: https://open.spotify.com/episode/3aJUF3yrzbJoXaaOCdi4Zh

- PisandoTierra - Programa 3: Ciudades y comunidades sostenibles - ODS 11

5 Según Lankshear, C. y Knobel, M. (2008), el RSS significa Really Simple Syndication, código de alimentación diferente a la dirección de la página real (p. 168) 
O Spotify: https://open.spotify.com/episode/1ZkWuxcerTxK1Hzdc9xRkq

- \#PisandoTierra - Programa 4: Producción y consumo responsable - ODS 12

○ Spotify: https://open.spotify.com/episode/7KsLFkWIWTnZ5QVKDmqPQb

- \#PisandoTierra - Entrevista/Programa 3 - Fiorella Herrera

O Spotify: https://open.spotify.com/episode/3fsKXTHgjYjegg40QRsH8R

- \#PisandoTierra - Programa 5: Acción por el clima - ODS 13

O Spotify: https://open.spotify.com/episode/3JIN0TFLnrg69WU3BOyjTs

- \#PisandoTierra - Entrevista/Programa 2 - Robinson Calderón

○ Spotify:https://open.spotify.com/episode/6HWb46ipqVc6X9IBXqmxHw

- \#PisandoTierra - Programa 6: Ganadora \#2 y resumen de los programas

○ Spotify: https://open.spotify.com/episode/2EzUDIbKBTZankFBLkfKQM

- \#PisandoTierra - Programa 7: Trabajo decente y crecimiento económico - ODS 8

o Spotify: https://open.spotify.com/episode/4u49x5Fen5PLOoho6o10Ca

- \#PisandoTierra - Entrevista/Programa 7 - Elizabeth Mariscal

O Spotify: https://open.spotify.com/episode/7rlLKmwSc7HRd9BTJgonn3

- \#PisandoTierra - Programa 8: Igualdad de género - ODS 5

○ Spotify: https://open.spotify.com/episode/3KVULi7qHWBifbZV6j82or

- \#PisandoTierra - Entrevista/Programa 8 - Jheinser Pacaya

○ Spotify: https://open.spotify.com/episode/5X6IWspRKFEhekJyrvyNML

- \#PisandoTierra - Programa 9: Alianzas para lograr los objetivos - ODS 17

○ Spotify: https://open.spotify.com/episode/57NvjDxwzkxCOk5iFwiubu

- \#PisandoTierra - Entrevista/Programa 9 - Pamela Navarrete

O Spotify: https://open.spotify.com/episode/0E2vTbMdPsPFwFUfNwvdLX

- \#PisandoTierra - Programa 10: Educación de calidad - ODS 4 
O Spotify: https://open.spotify.com/episode/1SxXD9KkVkACt1efqD7AG3

- \#PisandoTierra - Entrevista/Programa 10 - Susan Torres

○ Spotify: https://open.spotify.com/episode/7jpsmCzuTFbfUc8mX74Q3i

- \#PisandoTierra - Programa 11: Vida de ecosistemas terrestres - ODS 15

○ Spotify: https://open.spotify.com/episode/36r1n8BdjKewP6kFMEkk86

- \#PisandoTierra - Entrevista/Programa 11 - Fernando Ruiz y Marjorie Reffray

○ Spotify: https://open.spotify.com/episode/2z1PdQL8ceiGcsGFpk7q6s

- \#PisandoTierra - Programa 12: Reducción de las desigualdades - ODS 10

○ Spotify: https://open.spotify.com/episode/0IDiFOoToiYaUway0DwDNB

- \#PisandoTierra - Entrevista/Programa 12 - Clara Yolks

○ Spotify: https://open.spotify.com/episode/4WiQ10BXUSdGEnWU44xIlf 


\section{CAPÍTULO IV: LOGROS Y RESULTADOS}

\subsection{Interacción del contenido}

\subsubsection{Interacción en Facebook}

La interacción del público con el podcast fue uno de nuestros indicadores para analizar la llegada de nuestros canales de comunicación en redes sociales. De igual forma, Pisando Tierra también buscaba interactuar con otras páginas relevantes a la temática etiquetando a las organizaciones o compartiendo contenido relevante.

Algunos ejemplos de las interacciones:

- En el programa \#3 se entrevistó a Fiorella Herrera, fundadora de We Can Be Heroes, en torno al ODS 11: Ciudades y comunidades sostenibles. Realizamos una publicación en nuestra página y se etiquetó a la asociación. Ellos, después, compartieron dicho post generando mayor interacción con usuarios que no necesariamente nos seguían o conocían.

- En el programa \#4 se trató el ODS 12: Producción y consumo responsables, para el cual se entrevistó al fundador de Evea, empresa B peruana de calzado hecho de caucho natural. En este caso, Cristian compartió la publicación desde su perfil personal de Facebook, lo cual también generó nuevos likes para nuestra página.

- Otras publicaciones de usuarios que no entrevistamos también han contribuido de manera positiva nuestro alcance. Estas fueron compartidas de manera orgánica, lo cual nos permite llegar a una mayor audiencia.

\subsubsection{Interacción en Instagram}

- El Blog de Trin en Instagram compartió en una de sus historias el canal de Spotify de Pisando Tierra, lo cual generó llegada a un público diferente. 
- Alcanzamos mayor impacto en públicos de otras edades al momento de que cuentas como Siento mi amazonia, Qarma.pe, Actibicimo, Recíclame.pe y otras más nos etiqueten en sus historias. De igual forma, se realizó un sorteo usando el hashtag \#Sientomiamazonia generando movimiento a nivel internacional a través de esa etiqueta.

- La mayor interacción obtenida fue en la publicación del tercer sorteo y también se generaron mayores visitas al perfil, llegando a 165 en promedio por casi dos semanas.

\subsubsection{Interacción en otras plataformas}

Por otro lado, se compartió el contenido de Pisando Tierra en otras redes sociales como LinkedIn, Twitter o grupos de Facebook desde nuestras cuentas personales (Anexo 8).

- Se logró interacción desde una cuenta personal de LinkedIn al publicar el canal del podcast. El resultado fue una mayor cantidad de visitas durante esos días al canal, así como reacciones positivas por parte de adultos ubicados en Colombia y España. Una de ellos incluso nos invitó a formar parte de su podcast sobre sostenibilidad.

- A través de nuestras cuentas personales en Twitter compartimos la cuenta de Pisando Tierra en Spotify. El resultado fue que este link fue retwitteado y recibimos atención por parte de otros usuarios no necesariamente contemplados dentro del público objetivo de nuestro contenido.

- Los concursos realizados generaron movimiento en las páginas por las personas que ganaron los sorteos. Ellas han compartido los premios y la publicación siendo un factor importante para ganar mayor visualización (Anexo 9).

\subsection{Métricas en plataformas de reproducción}

Las métricas de las plataformas que se utilizaron pasaron por constante revisión para así registrar los cambios en la audiencia y el movimiento del podcast hasta la fecha. Las estadísticas nos muestran el género, la edad o espacio geográfico del oyente en cada programa, así como la totalidad de sus interacciones (clics, tiempo de escucha). 
El podcast Pisando Tierra está presente en 8 plataformas actualmente, de las cuales una es para almacenar los audios y las restantes de distribución. Este punto es importante para todo creador de podcasts o podcaster porque al subir contenido sonoro a internet se necesita un lugar dentro de una web para alojar dichos audios (hosting). Al comenzar el proyecto, se usó Soundcloud para subir contenido a la web y mediante un RSS se actualizaba automáticamente en otras plataformas como Spotify o iVoox. Sin embargo, esta plataforma daba una restricción, lo cual limitaba al proyecto. Por dicho motivo, el podcast se mudó a Anchor, la cual brinda libertad de alojamiento, entre otros servicios, al usuario de forma gratuita. En cuanto a Spotify siguió siendo el medio principal para que el público escuche el contenido.

\subsubsection{Anchor}

Es una plataforma de almacenamiento gratuita que da muchos servicios al usuario. Uno de ellos, es poder subir contenido sin tiempo máximo total para luego acceder a un plan de paga. Además, se puede grabar en línea y editar, de forma sencilla y simple, dentro de la plataforma.

En el análisis de data se tomó en cuenta los próximos números de forma complementaria:

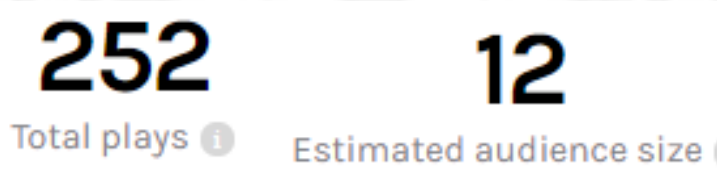

- Total plays: Número total de todas las veces que el podcast haya sido reproducido en todas las plataformas desde la fecha de uso de la plataforma.

- Estimated audience size: Promedio de reproducciones.

Anchor realiza un promedio de la actividad que registra en su plataforma y en todas las que se ha distribuido el podcast como Spotify, Apple podcast, Google Play, iVoox, entre otras. En este caso, el 252 (total plays) se refiere a la combinación de veces que se ha escuchado o descargado los episodios, en general, en todas las plataformas que se tenga. Además, te da un número estimado de audiencia, en este caso 12 (estimated audience size), a los 30 días de la publicación del episodio. 
Por otro lado, nos muestra un gráfico con la cantidad de clics que se ha dado en los episodios desde el día de su publicación ${ }^{6}$.

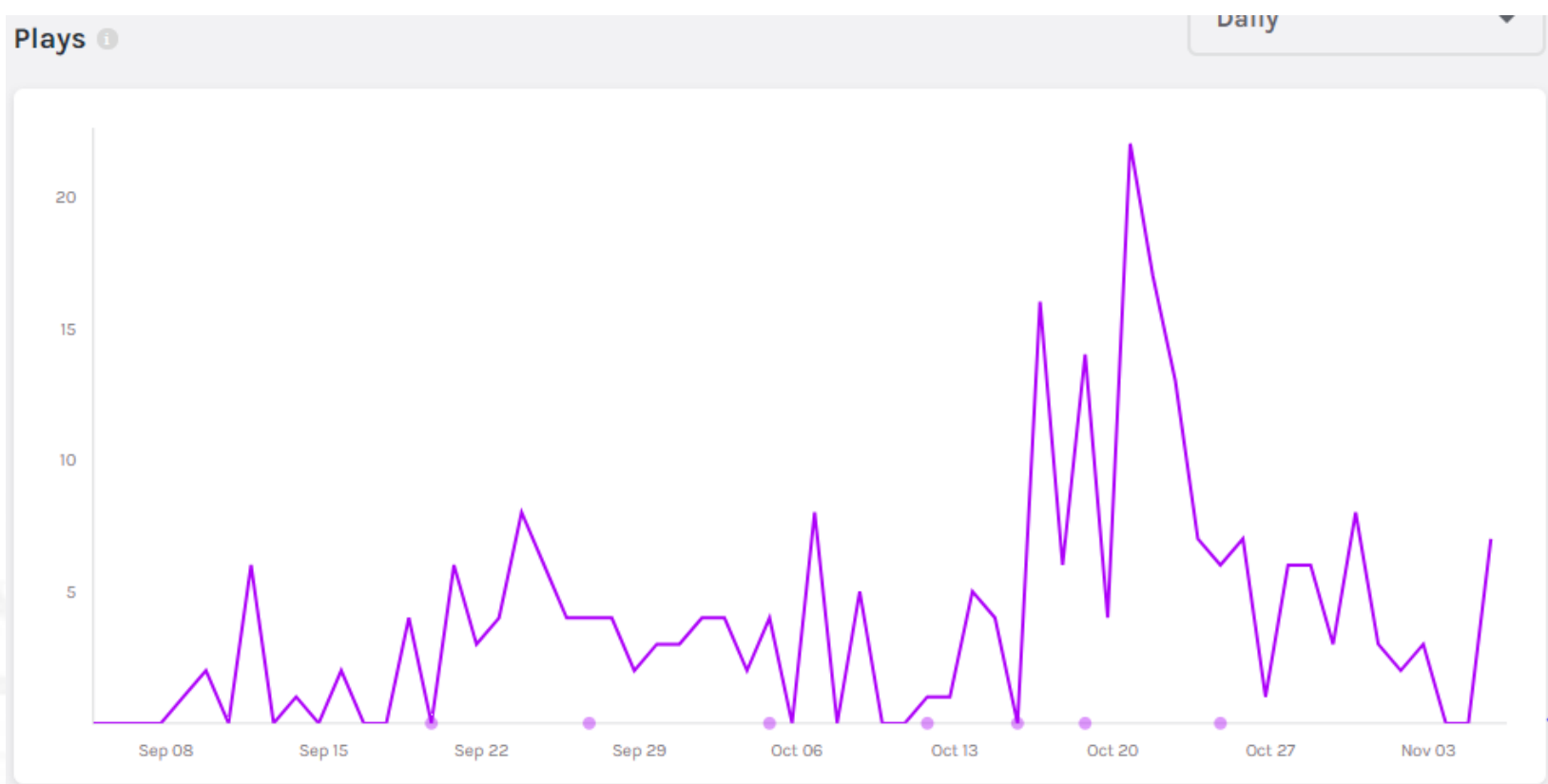

También, nos muestra un cuadro con los programas con más reproducciones desde el momento en el que la plataforma ha estado recolectando los datos.

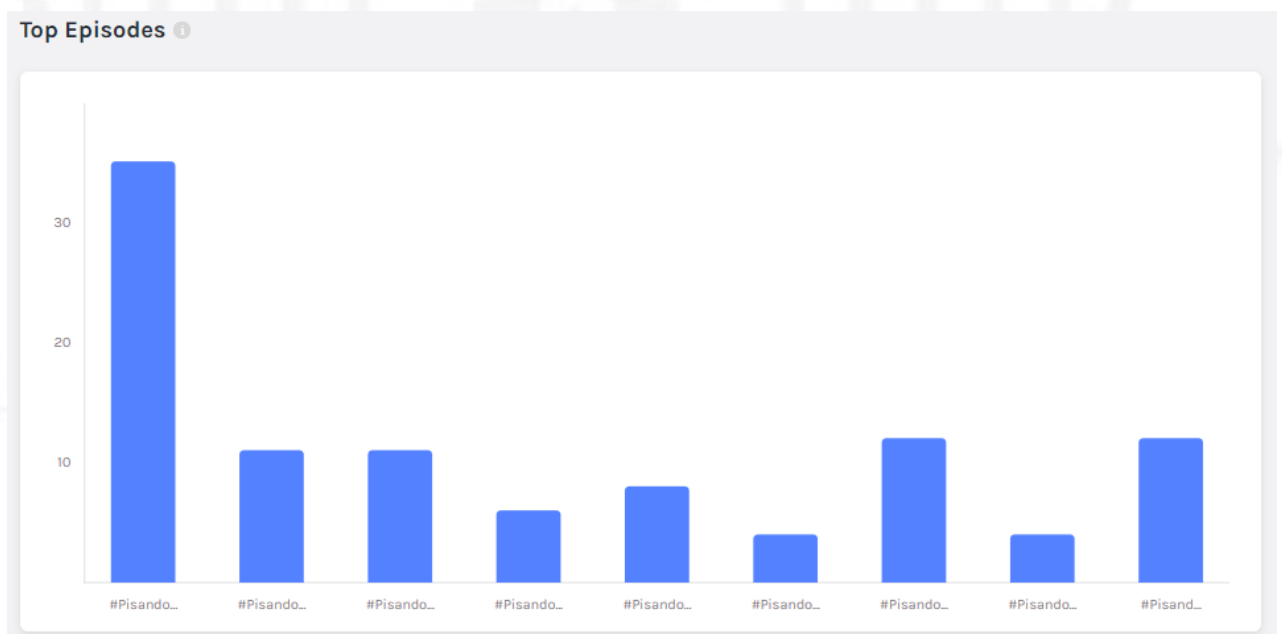

La mayor cantidad de reproducciones o descargas las tiene el primer episodio durante todo el tiempo que se ha estado compartiendo el podcast. En segundo lugar, se tiene dos programas nuevos con 12 reproducciones. Estos son los episodios 10 y 11, en los cuales

\footnotetext{
${ }^{6}$ Se debe recordar que en este gráfico solo presenta actividad después del 8 de setiembre, ya que ese día se cambió de plataforma de almacenamiento.
} 
hablamos sobre el ODS 4: Educación de calidad y ODS 15: Vida de ecosistemas terrestres, respectivamente.

Además, nos da información sobre la ubicación geográfica de los usuarios que escuchan el podcast. La mayoría de nuestros oyentes son de Perú, seguidos de Estados Unidos, según la estadística de Anchor. También se puede conocer la plataforma de reproducción donde más han escuchado, la cual en nuestro caso es Spotify.

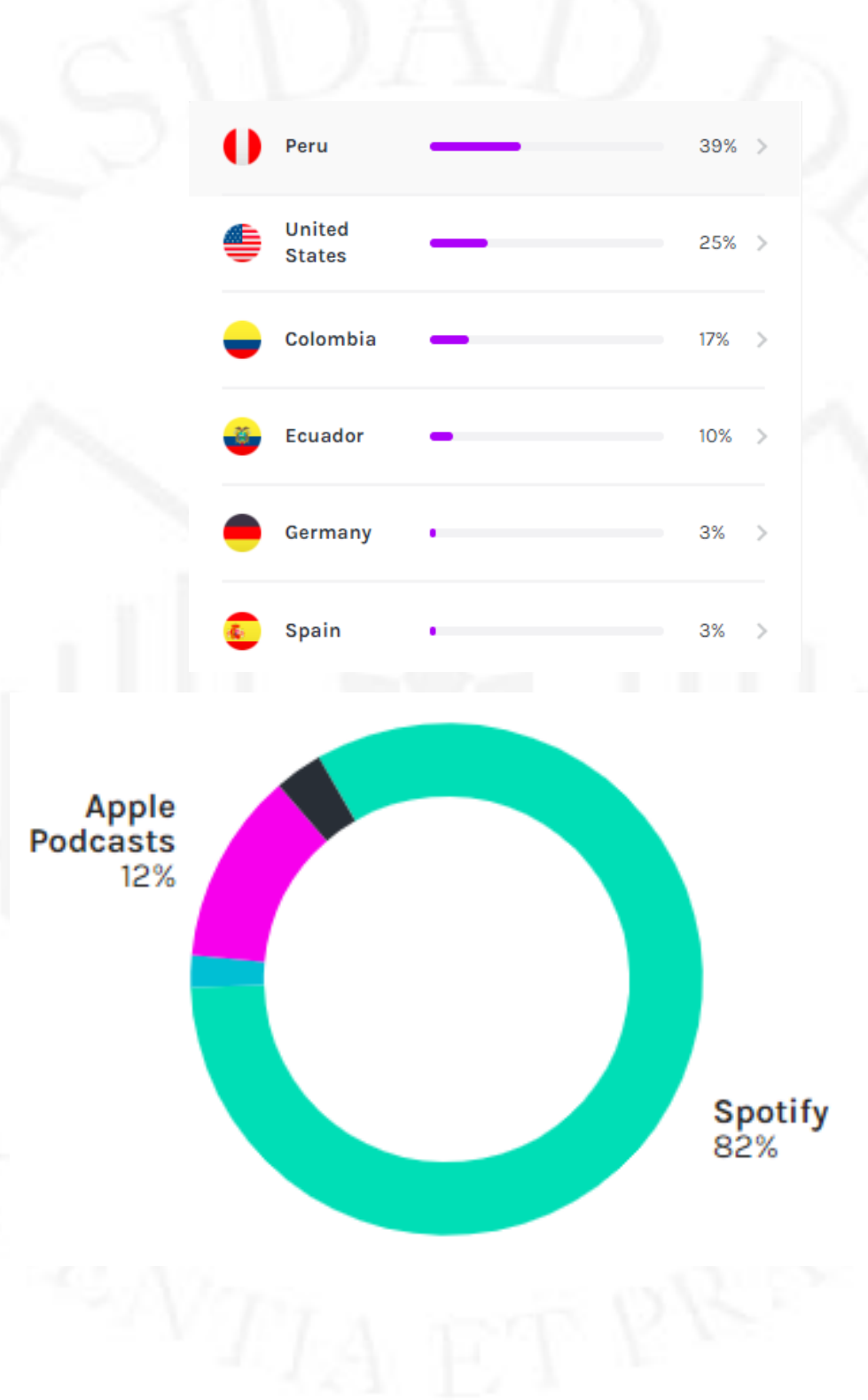

\subsubsection{Spotify}

En esta plataforma digital no se puede almacenar audio siendo solo de distribución de contenido ajeno. El acceso se obtiene mediante el RSS que se generó en la plataforma de alojamiento: SoundCloud y posteriormente, Anchor. 
Siendo esta una red especializada en contenido sonoro como música y, actualmente, podcasts, las estadísticas lanzadas son más detalladas y útiles al momento de analizar el alcance obtenido.

En julio de este año nuestro alcance orgánico fue el siguiente:

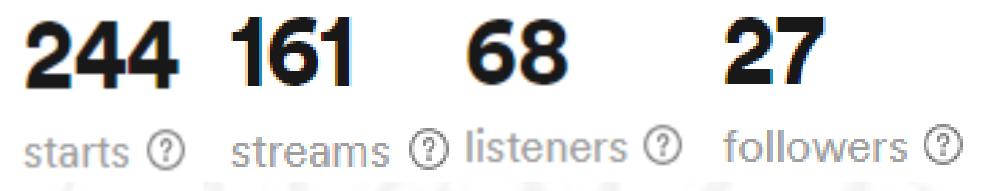

Actualmente, en noviembre, hemos duplicado las cifras teniendo un mayor alcance de público como se va a explicar a continuación:

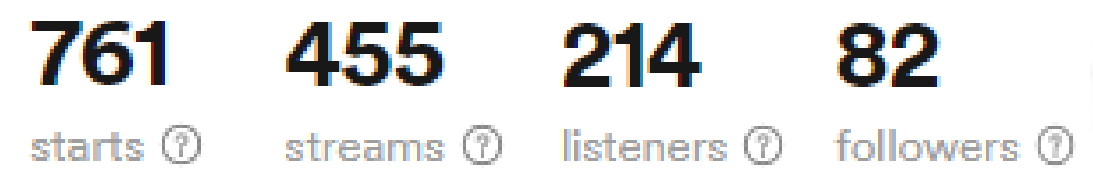

- Starts: Todos los usuarios de Spotify que han escuchado del segundo 0 a más de cualquier episodio del catálogo.

- Streams: Todos los usuarios de Spotify que han escuchado de 60 segundos a más en cualquier episodio del catálogo.

- Listeners: Usuarios únicos de Spotify que han empezado cualquier episodio del catálogo. (Solo se cuenta 1 vez así haya tenido mayor número de interacciones en Spotify)

- Followers: Número de usuarios de Spotify que le han dado seguir al canal.

Hasta la última revisión de las estadísticas, se tenía 82 followers (seguidores) quienes al estar suscritos al canal pueden tener conocimiento del estreno de nuevos episodios sin la necesidad de estar pendientes a que hagamos actualizaciones. En las siguientes métricas, podemos observar que se registraron 761 starts, lo cual nos indica las veces que se comenzó a escuchar cualquier de los programas del catálogo sin importar su tiempo de permanencia ni las veces que un mismo usuario haya dado play al audio, solo registra todas las entradas o clics percibidos. Sin embargo, nos dan otro dato, los listeners que, en este caso, ascienden a 214 son aquellos usuarios únicos que han comenzado cualquier episodio del catálogo. 
Por último, se tiene 455 streams quienes son usuarios de Spotify que han escuchado 60 segundos o más de algún programa. Esto resulta en un grupo de 356 usuarios que no se han quedado un minuto escuchando algún programa. Es interesante este punto porque en el anterior registro se tenía 93 personas que no se quedaban más de un minuto y este número ha aumentado, lo cual nos lleva a pensar en una estrategia para retener al usuario a poder escuchar más de un minuto y en lo óptimo, todo el programa. De igual forma, el dato anterior, los 93 usuarios que no se quedan más de un minuto, no es sobre usuarios únicos y ello en realidad podría resultar en 1 persona que no escucha por más de un minuto 93 veces como un grupo de personas que no escuchan más de 1 minutos repetidas veces. Por ello, también es importante recalcar el alza de 68 listeners a 214 quienes sí son usuarios únicos. Esto quiere decir que hay 214 usuarios que han escuchado el podcast sin importar el tiempo o cuántas interacciones realizaron dentro del perfil.

Esto tiene relación con los 81 followers -quienes también han aumentado- con la búsqueda de una razón por la que estos 130 usuarios no se vuelven followers del podcast sino simplemente usuarios que han interactuado con los programas siendo esta una buena oportunidad de analizar el contenido.

- Starts y streams en Pisando Tierra Podcast:

Gracias al gráfico podemos observar a mayor detalle lo anteriormente mencionado sobre la diferencia entre los usuarios que comenzaron un episodio con aquellos que escucharon más de 60 segundos. Podemos analizar dos cosas. La primera imagen muestra un dato del 15 de octubre donde la brecha entre starts y streams es más amplia, teniendo 24 y 4 usuarios respectivamente. En el segundo caso, el 16 de octubre la diferencia disminuye teniendo 13 starts y 10 streams.

Starts \& Streams

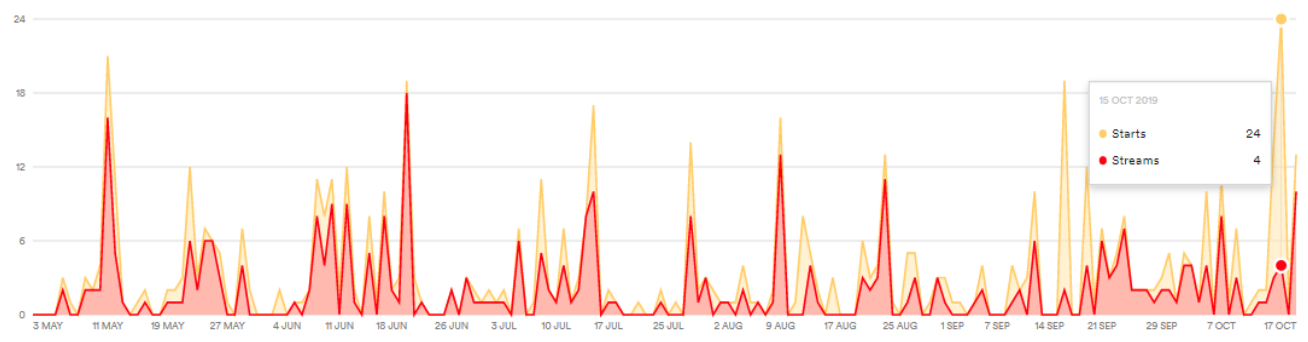




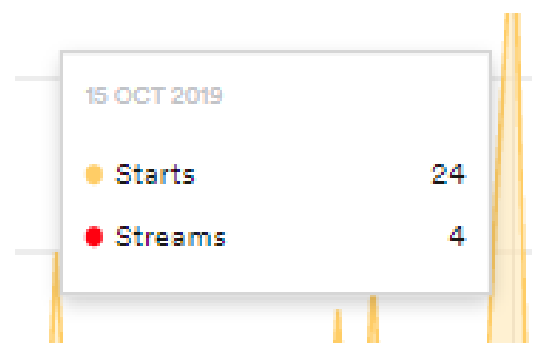

Starts \& Streams
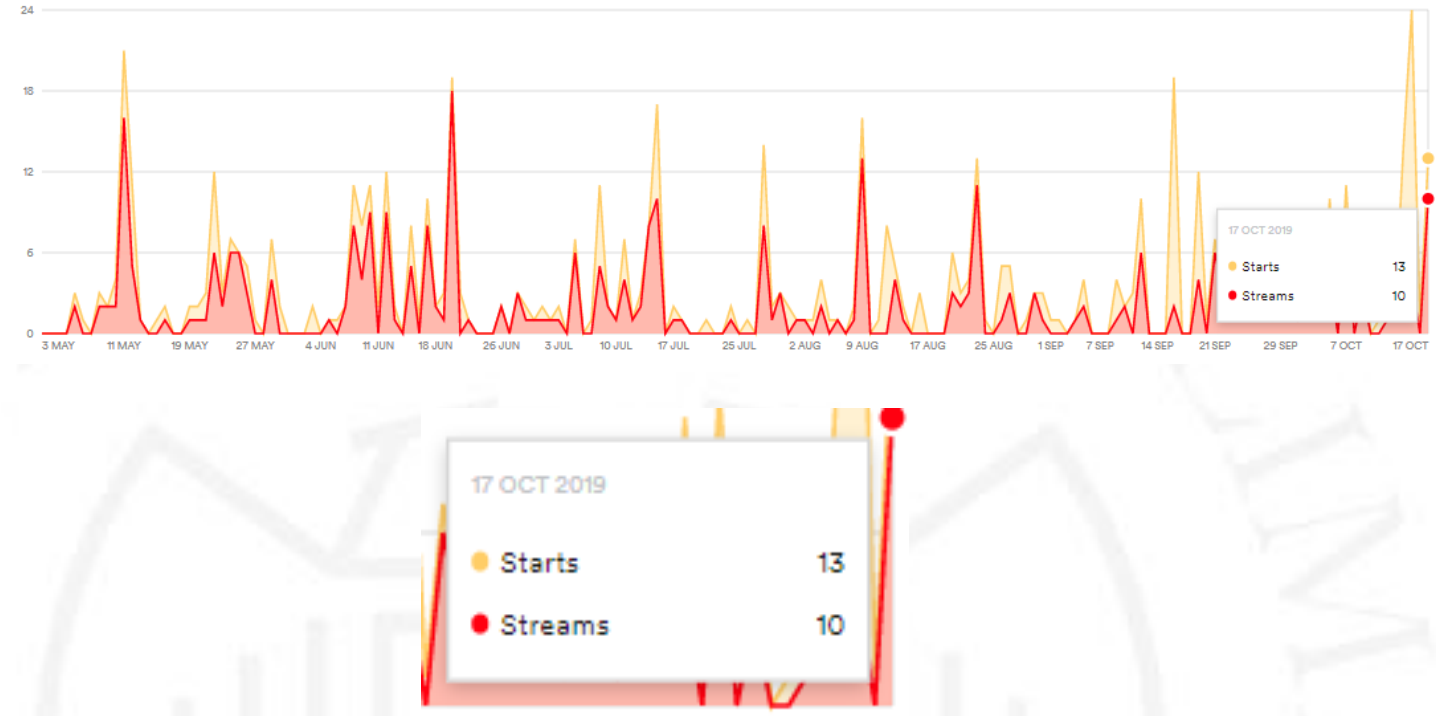

- Listeners de Pisando Tierra Podcast:

Para completar la información anterior, se tiene el gráfico de listeners, usuarios únicos. El 16 de octubre se registró la actividad de 4 usuarios único-registrados. Es decir, entre todos estos oyentes han dado 24 clics, 6 en promedio cada uno, a uno o varios audios y 4 de estas interacciones en los audios han registrado un tiempo mayor de 30 segundos. Lo cual podría resultar en un audio completo por cada usuario.

Listeners

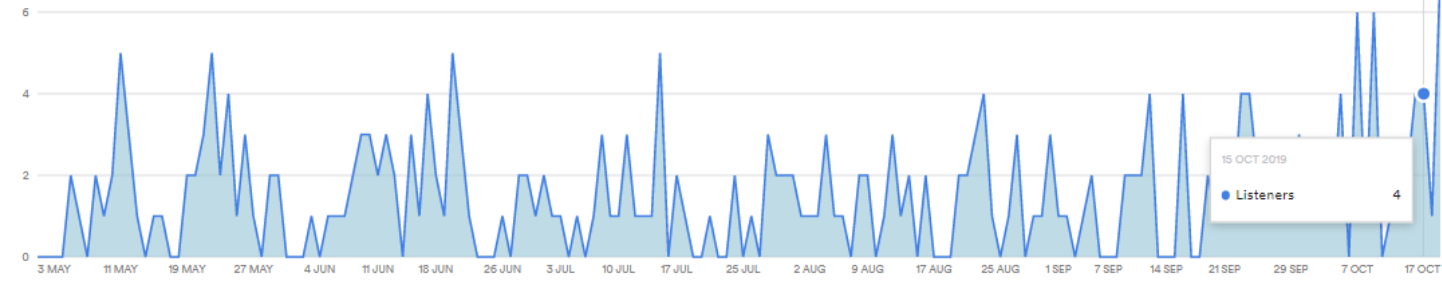




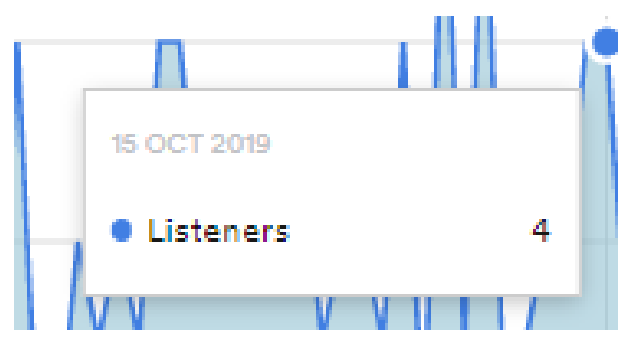

Por otro lado, el 17 de octubre se registró la actividad de 7 usuarios únicos, 13 starts y 10 streams. Esto se puede entender que los 7 han empezado un audio $\mathrm{y}$, por lo menos, uno ha debido seguir navegando en el perfil del podcast o escuchado más de 30 segundos varias veces, pero no confirma si todos los usuarios han escuchado más de 30 segundos. Lo que sí se puede tener en cuenta, es que, por lo menos dos usuarios, han debido escuchar más de 30 segundos varios audios.
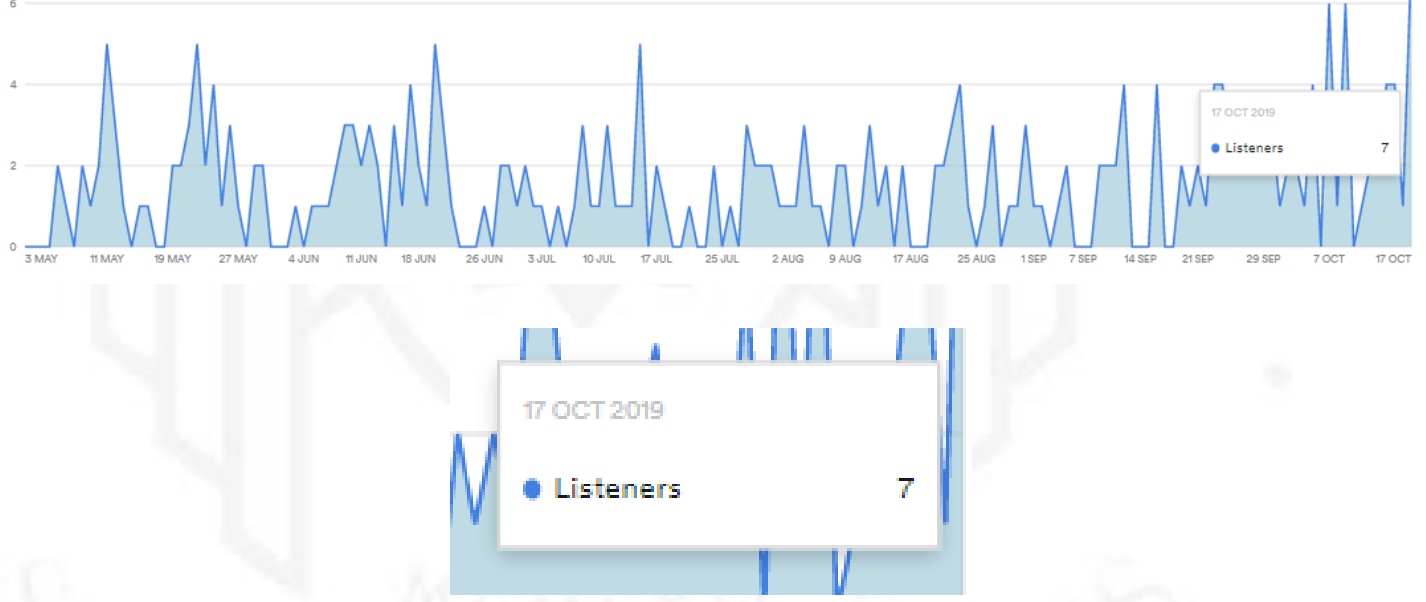

- Followers en Pisando Tierra Podcast:

En la siguiente gráfica se aprecia la subida paulatina de followers (seguidores) a lo largo de la existencia de los programas. Esto se da por la constante actualización y subida de contenido en las plataformas que usamos. 


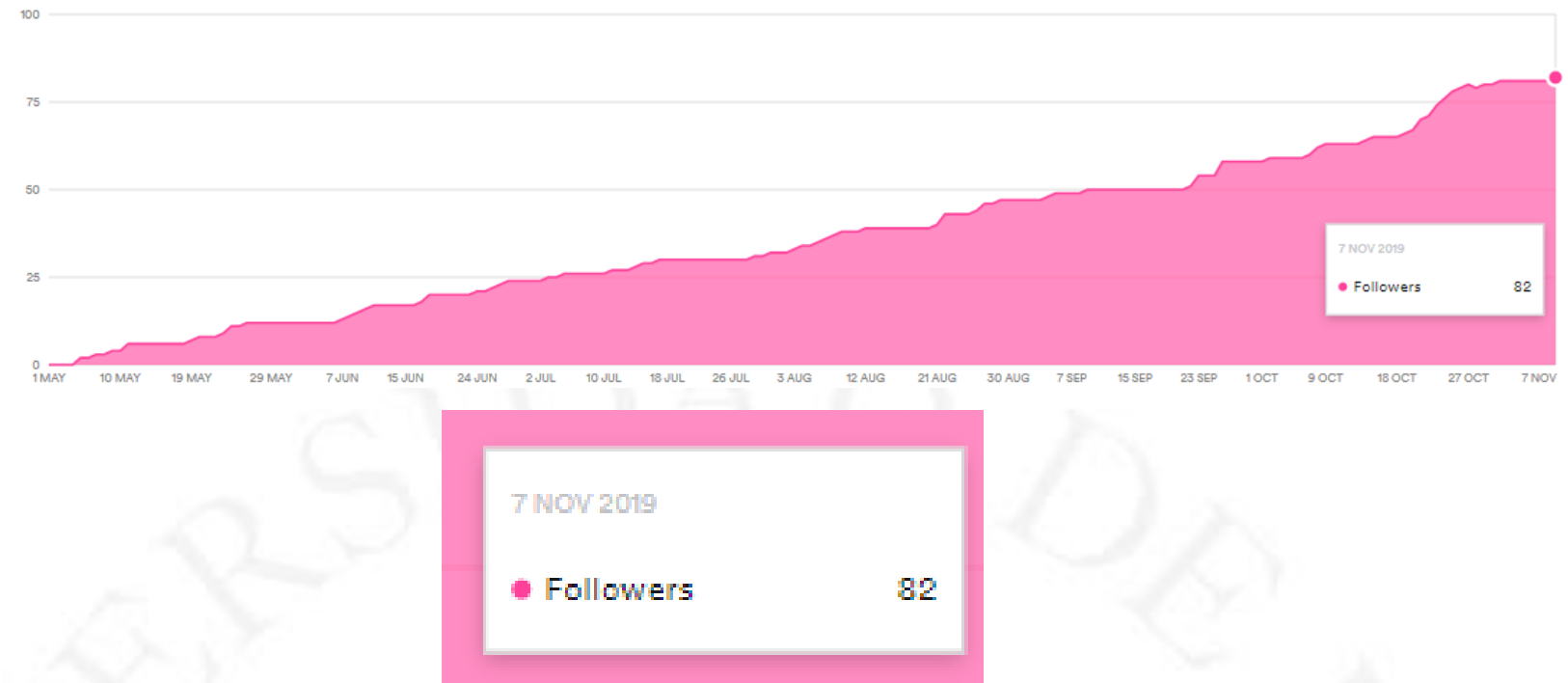

- Sexo del oyente en Pisando Tierra Podcast:

Por otro lado, el sexo es importante para saber si el contenido está siendo llamativo o para quién es llamativo. Ante un reporte anterior de las métricas, el porcentaje de escucha de mujeres ha aumentado de $54 \%$ a $56 \%$ del total de oyentes, al igual que el porcentaje de usuarios que no especifican su género de $0 \%$ a $2 \%$, el porcentaje de hombres se ha mantenido en $37 \%$ y el género no binario ha disminuido de $9 \%$ a $5 \%$.

\section{Gender}

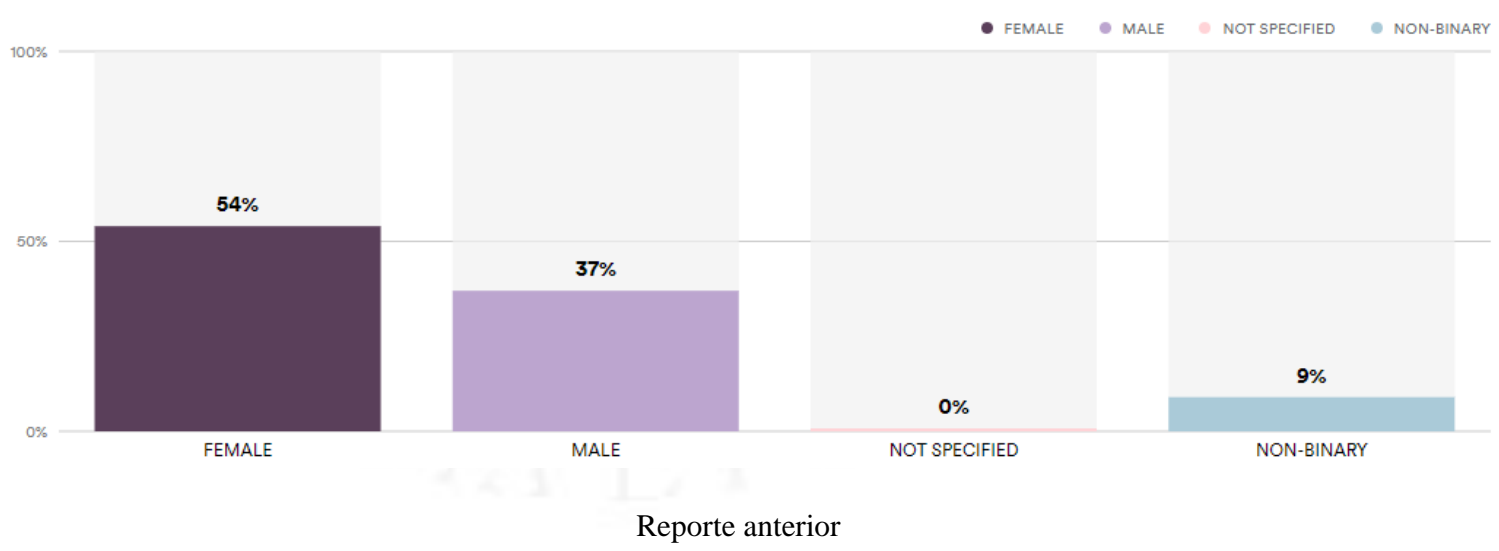



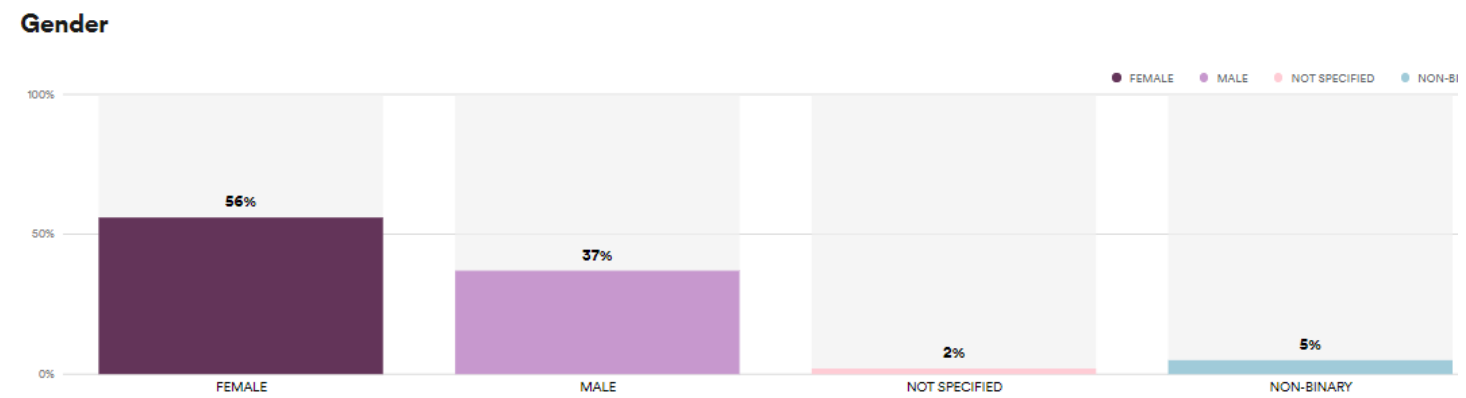

Reporte actual

Otro punto interesante de analizar es la baja de escucha entre usuarios no binarios de un $3 \%$ al $0 \%$, esto puede ser debido a la falta de referencia por temas que les pueda interesar o que le parezcan más atractivos en los ODS que hablamos todos los viernes.

- Edad del oyente de Pisando Tierra Podcast:

La estadística proporcionada por Spotify también nos muestra la edad, artistas preferidos y lugar de procedencia del oyente. En cuanto al primero, podemos ver que tenemos mayor cantidad de usuarios de 23-27 años, aunque haya disminuido entre julio y octubre de este año de $47 \%$ a $45 \%$, frente al grupo de 18-22 años, quienes han aumentado de $12 \%$ a $14 \%$. Sin embargo, actualmente podemos ver una presencia de hombres entre 18-22, quienes no tenían participación anteriormente.

\section{Age}

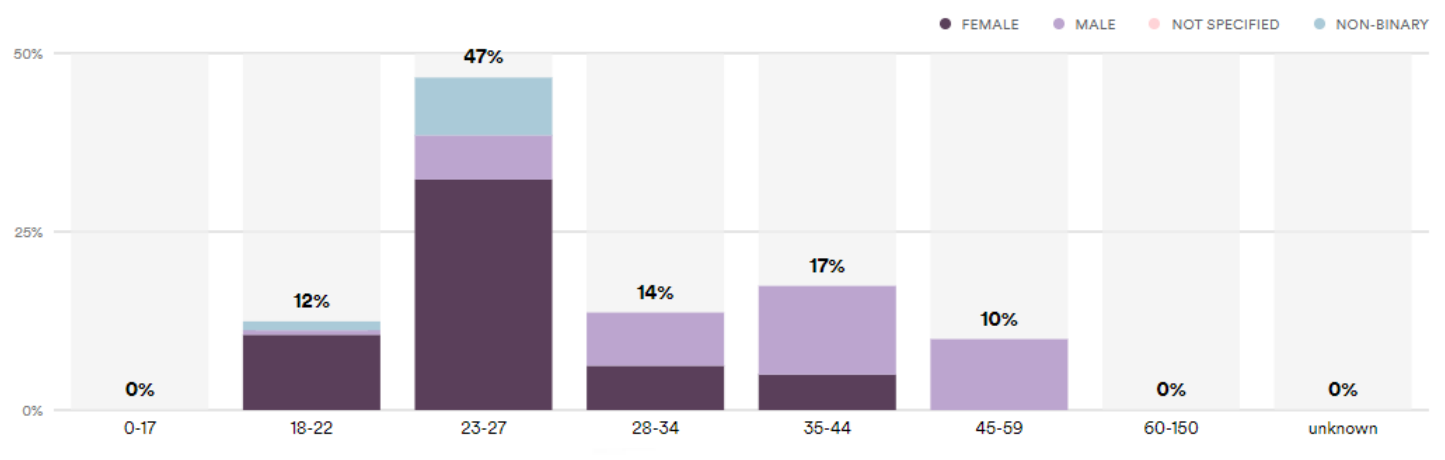

Reporte anterior 


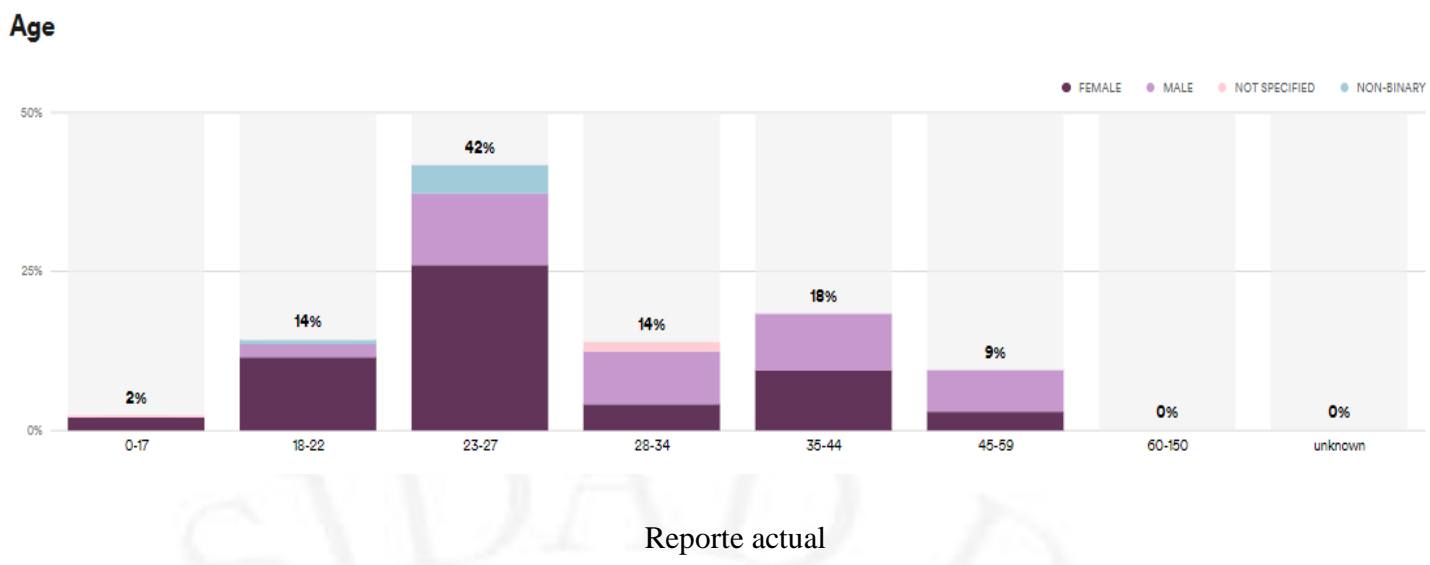

- $\quad$ Países donde se escucha Pisando Tierra Podcast:

Por último, en Spotify, se realiza una lista de países de donde pertenecen los streams (usuarios que escuchan más de 60 segundos cualquier contenido dentro del perfil) a lo largo del mundo, siendo Perú el país con mayor cantidad de streams. Esto se da por la misma nacionalidad del podcast que permite que Spotify, por los algoritmos que maneja, muestre el programa más rápido dentro del feed de los usuarios de Perú que de otra parte del mundo. Esto a comparación de lo presentado por Anchor, Estados Unidos se presenta en posición 9 frente al resto de países.

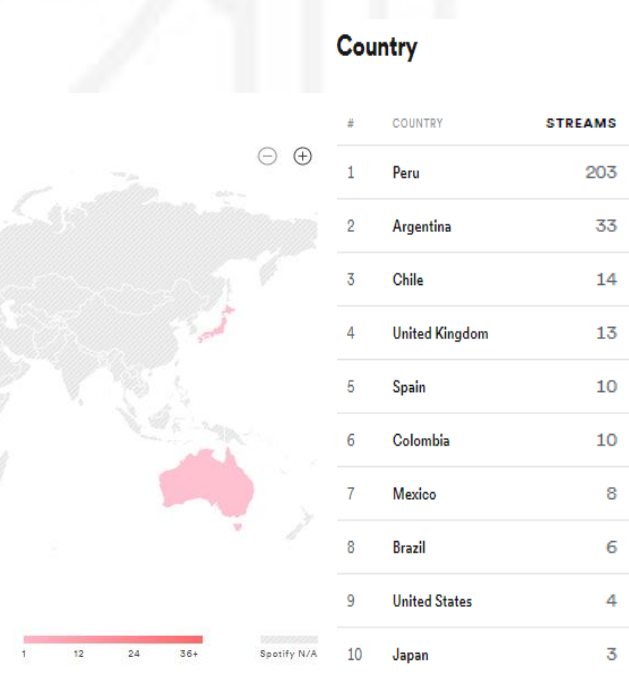




\section{CAPÍTULO V: LECCIONES APRENDIDAS}

Desde el esbozo de Pisando Tierra hubo un continuo aprendizaje sobre cómo manejar contenido sonoro más allá de la producción, ya que este proyecto ha implicado la elección de potenciales entrevistados, investigación teórica, creación de contenido en redes y administración de cuentas en Facebook e Instagram.

\subsection{Creación del podcast Pisando Tierra:}

Una sugerencia es investigar a modo comparativo sobre las estrategias de comunicación y el manejo de contenido de podcasts independientes frente a radios tradicionales. Además, al haber trabajado en formato de infomediario, la elección de las fuentes y la comunicación sencilla de las mismas fue muy importante para el manejo de contenido.

A comparación de otros formatos de grabación, fue un acierto utilizar realizar la mezcla de audio antes de publicar el contenido en una plataforma digital como Spotify. Para editar el audio se tuvo un banco de sonidos y música libre de derechos de autor para optimizar el tiempo de postproducción. Estos elementos sonoros nos ayudaron a generar una atmósfera contextual y brindar una experiencia agradable al oído del público. Asimismo, cabe resaltar la importancia de utilizar pistas royalty free, ya que esto supone total autonomía para compartir nuestro contenido cuidando el marco legal y autoría.

\subsection{Plataformas:}

Al comenzar el proyecto se tuvo que aprender la diferencia de las plataformas para podcasts; es decir, aquellas que sirven como alojamiento para subir contenido a internet y las de distribución, que funcionan como un amplificador. En cuanto a la elección de la plataforma, para alojar el contenido del podcast en la web, se usó SoundCloud, el cual brinda solo una cantidad de minutos limitados para subir audios en el plan gratuito; por ello, cambiamos de plataforma a Anchor, el cual ofrece al usuario mayor libertad para subir su contenido a la web. Conocer a profundidad los servicios y limitaciones que brinda cada plataforma para su uso ayuda al creador de contenido a hacer 
una elección acertada para el producto que quiera realizar. Creemos que esta información es importante porque así otros podcasters no se verán en la necesidad de migrar a otra plataforma sin costo para continuar con la publicación de sus episodios. Es decir, es importante la elección de una plataforma de distribución acorde a las necesidades del proyecto sonoro.

Ha sido muy importante elegir si queríamos salir en vivo o editar el contenido antes de subirlo a la plataforma. Debido a que elegimos editar cada grabación, se pudo incorporar una cuña de entrada a cada programa, el entrevistado tuvo libertad al momento de responder nuestras preguntas y pudimos regrabar algún momento que sentíamos fuera de la atmósfera inicial del programa. Además, el poder editar brinda un mayor control sobre la duración de los clips y regulación del volumen, así como inserción de efectos de sonido, según lo que el podcaster necesite.

Es necesario analizar los resultados del alcance del contenido publicado en una o dos plataformas: Spotify es una plataforma de distribución que entrega data puntual y necesaria a los creadores o personas que manejen estos datos. Al igual, es importante recordar que se debe investigar y encontrar una plataforma para almacenar el contenido -en Pisando Tierra fue Anchor- que se adapte a las necesidades del podcaster. Todo ello con el fin de poder recuperar información sobre el oyente y tener conocimiento sobre si los temas están siendo bien recepcionados por nuestros usuarios.

El proyecto tuvo una acogida mayor a la imaginada al ser un tema nicho. Por ello, es importante tener en cuenta las oportunidades de crecimiento del podcast como buscar aliados estratégicos que puedan proveernos de información especializada sobre proyectos realizados en torno a los Objetivos de Desarrollo Sostenible y/o financiación. Trabajar tomando como base los ODS permite presentar este proyecto a nivel internacional y que continúe en vigencia la temática. 


\section{REFERENCIAS}

Bonini, T. (2015). The 'Second Age' of Podcasting: reframing Podcasting as a New Digital Mass Medium. En Cuaderns del CAL, 41, vol. XVIII.

Cebrián-Herreros, M. (2009). La radio en la convergencia multimedia. Barcelona: Gedisa.

Datum (2017) ¿En qué se diferencian los millennials del Perú? Recuperado de: http://www.datum.com.pe/new_web_files/files/pdf/Millennials.pdf, el $12 \mathrm{de}$ julio de 2018.

Deloitte (2019). Encuesta a la generación millennial 2019. Recuperado de: https://www2.deloitte.com/content/dam/Deloitte/es/Documents/humancapital/Deloitte-ES-HC-Millennial-Survey-2019.pdf, el 12 de julio de 2019.

García-Marín, D. y Aparici, R. (2018). Nueva comunicación sonora. Cartografía, gramática y narrativa transmedia del podcasting. El profesional de la Información, 17, 1071-1081. Recuperado de:

Cóndor, J. (2018). 60\% de internautas escucha todos los días algún contenido de audio digital. Gestión. Recuperado de: https://gestion.pe/economia/empresas/60internautas-escucha-dias-contenido-audio-digital-251048, el 12 de julio de 2019.

Ipsos. (2018). Millennials: Mitos y realidades. Recuperado de: https://www.ipsos.com/sites/default/files/ct/publication/documents/201806/ipsos_peru_-_millennials_0.pdf, el 13 de julio de 2018.

Lankshear, C., Knobel, M. (2008) Nuevos alfabetismos. Su práctica cotidiana y el aprendizaje en el aula. España: Ediciones Morata

PNUD. (s.f.). Objetivos de Desarrollo Sostenible. Recuperado de: http://www.undp.org/content/undp/es/home/sustainable-developmentgoals.html, el 01 de julio de 2019.

Podcast Statistics. (2019). Recuperado de: https://musicoomph.com/podcast-statistics/, el 10 de julio de 2019.

Romero, S. (2018). Día Mundial de la Radio: los 'podcast' ya suenan con fuerza. BBVA. Recuperado de: https://www.bbva.com/es/dia-mundial-radio-podcastya-suenan-fuerza/, el 8 de noviembre de 2019.

Sachs, J., Schmidt-Traub, G., Kroll, C., Lafortune, G. \& Fuller, G. (2019). Sustainable Development Report 2019. New York: Bertelsmann Stiftung and Sustainable Development Solutions Network (SDSN).

Santillán, V. (2015). Comunicación y medio ambiente: las radios comunitarias como garantes del desarrollo sostenible en el Perú, en la Agenda Climática Nacional 
post COP-20. Tesis para optar por el Título de Licenciado en Comunicación para el Desarrollo. Lima: PUCP.

Sellas, T. (2011). El Podcasting. La (r)evolución sonora. Barcelona: UOC.

Sicheri, S. (2018). El consumo de podcast crece en Perú en búsqueda de calidad y buenos contenidos. El Comercio Recuperado de:

https://elcomercio.pe/tecnologia/consumo-podcast-crece-peru-busqueda-calidadbuenos-contenidos-sergio-sicheri-noticia-587880-noticia/, el 8 de noviembre de 2019.

Velezmoro, K. (2019). El avance del podcast en el Perú. Convoca. Recuperado de: http://convoca.pe/convoca-radio/el-avance-del-podcast-en-el-peru, el 8 de noviembre de 2019. 
ANEXOS 


\section{ANEXO 1: ANTECEDENTES DE PROGRAMAS SOBRE SOSTENIBILIDAD}

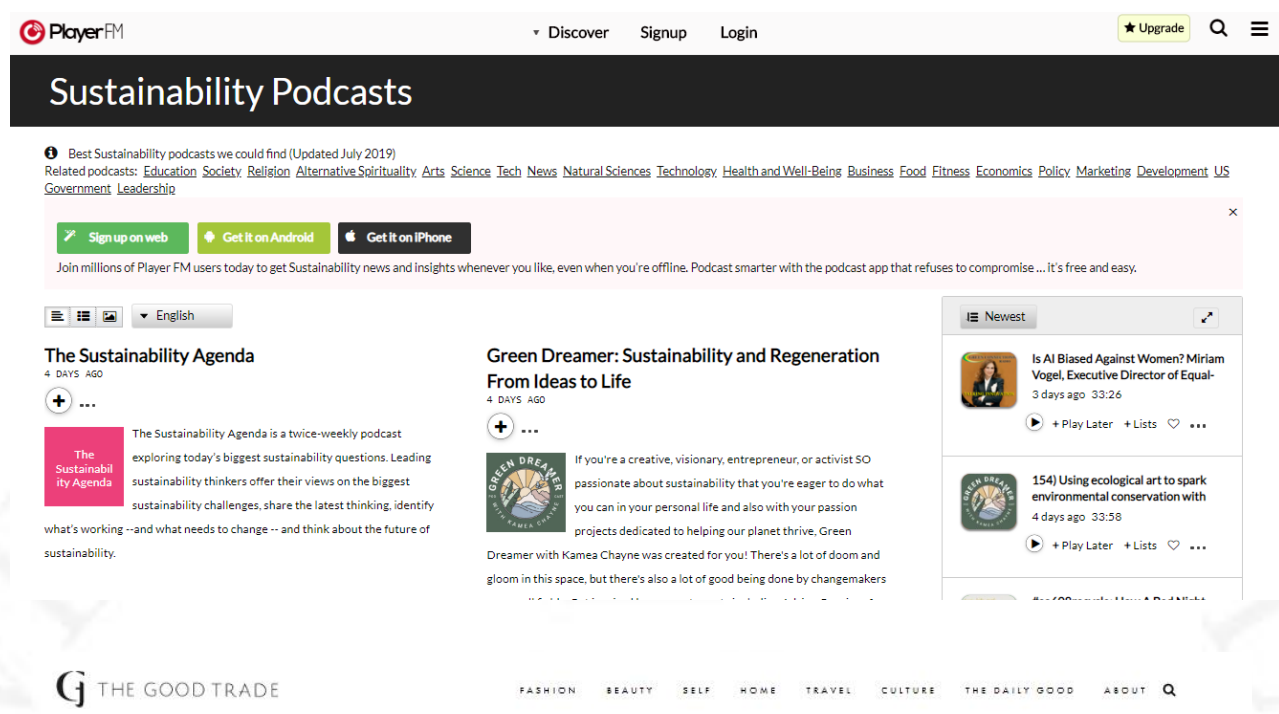

9 Thought-Provoking Podcasts To

Inspire Sustainable Living
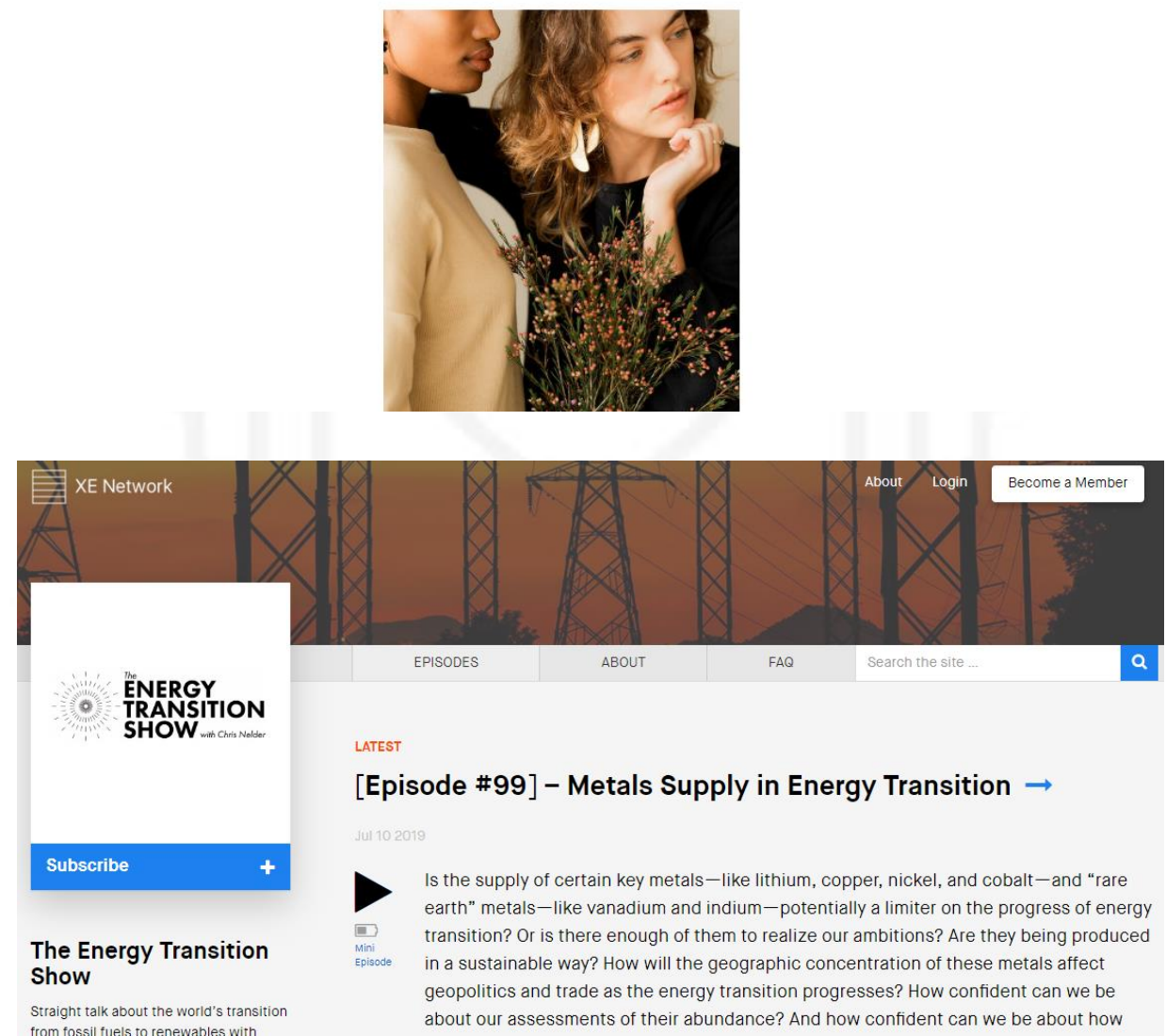

Podcasts en inglés que hablan sobre sostenibilidad 


\section{ANEXO 2: GUIÓN DEL PROGRAMA}

\section{Programa 4: Producción y consumo responsable (ODS 12)}

MO: Hola holaaa

MJ: ¡Esas fueron las pistas sobre el tema de hoy!

MO: Algo les dice sobre el uso del plástico, ¿cierto? Muy de la mano con lo que vimos en el capítulo anterior sobre Comunidades sostenibles

MJ: Sí, Moni, pero hoy veremos otro ODS. EI ODS 12 es Producción y consumo responsable.

MO: Wow. Eso se refiere a empresas e incluso a nosotros mismos, porque nosotros podemos optar por una opción ecoamigable al momento de comprar, comer o vestir.

MJ: Totalmente. A veces es difícil encontrar algo que sea responsable con el medio ambiente y la sociedad, pero es muy gratificante saber que sí existen esas alternativas. Por eso, hoy hemos invitado a una marca peruana

MO: Que tienen una visión distinta a comparación de otra empresas de calzado y nos van a contar hoy sobre Evea.

\section{ENTREVISTA a Cristian de Evea}

1. ¿Cómo surgió el emprendimiento de Evea?

2. ¿Por qué es importante la producción con un mínimo impacto ambiental?

3. Cuéntanos lo positivo y negativo de trabajar en un área protegida del Perú

MO: Me han dado muchas ganas de comprarme una de las zapatillas, realmente.

MJ: Yo hoy me puse mis Evea jajaja así estoy en sintonía con el medio ambiente.

MO: Y como queremos que ustedes también puedan usar productos conscientes con la huella socioambiental, vamos a dejarles un sorteo en la página de Facebook de Pisando Tierra.

MJ: Entren ya a la página y sigan los pasos para ganarse el segundo pack ecológicooo. 
ANEXO 3: LISTA DE TEMAS Y DE ENTREVISTADOS

\begin{tabular}{|c|c|}
\hline Programa & Entrevistado \\
\hline $\begin{array}{l}\text { - Tema 1: Introducción sobre } \\
\text { sostenibilidad }\end{array}$ & $\begin{array}{l}\text { Rosa Bonilla: Jefe de Relaciones } \\
\text { Institucionales y Sostenibilidad de } \\
\text { Entel Perú }\end{array}$ \\
\hline $\begin{array}{l}\text { - Tema 2: Energía asequible y no } \\
\text { contaminante (ODS 7) }\end{array}$ & $\begin{array}{l}\text { Robinson Calderón: Gerente general de } \\
\text { Innovación ambiental }\end{array}$ \\
\hline $\begin{array}{l}\text { - Tema 3: Ciudades y comunidades } \\
\text { sostenibles (ODS 11) }\end{array}$ & $\begin{array}{l}\text { Fiorella Herrera: Fundadora de ONG We } \\
\text { can be heroes }\end{array}$ \\
\hline $\begin{array}{l}\text { - Tema 4: Producción y consumo } \\
\text { responsable (ODS 12) }\end{array}$ & $\begin{array}{l}\text { Cristian Gutiérrez: Co-fundador de Evea } \\
\text { Ecofashion }\end{array}$ \\
\hline $\begin{array}{l}\text { - Tema 5: Acción por el clima (ODS } \\
\text { 13) }\end{array}$ & Audios de los oyentes del programa \\
\hline $\begin{array}{l}\text { - Tema 6: Resumen de los primeros } \\
\text { ODS comentados }(7,11,12,13) \mathrm{e} \\
\text { introducción a Agua limpia y } \\
\text { saneamiento (ODS 6) }\end{array}$ & $\begin{array}{l}\text { Ganadora del segundo sorteo. Valeria } \\
\text { Radó: Comunicadora social }\end{array}$ \\
\hline $\begin{array}{l}\text { - Tema 7: Trabajo decente y } \\
\text { crecimiento económico (ODS 8) }\end{array}$ & $\begin{array}{l}\text { Elizabeth Mariscal: representante de } \\
\text { marca social Ayllu Ruwasunchis de la } \\
\text { ONG Ruwasunchis }\end{array}$ \\
\hline - Tema 8: Igualdad de género (ODS 5) & $\begin{array}{l}\text { Jheinser Pacaya: codirector y } \\
\text { programador del Festival } \\
\text { Internacional de Cine Gay Lésbico } \\
\text { Trans en Lima, Outfest Perú. }\end{array}$ \\
\hline - Tema 9: Alianzas para lograr los & Pamela Navarrete: Co-fundadora de \\
\hline
\end{tabular}




\begin{tabular}{|l|l|}
\hline objetivos (ODS 17) & Matchcota Perú \\
\hline - Tema 10: Educación de calidad (ODS & $\begin{array}{c}\text { Susan Torres: Jefa del Programa de } \\
\text { Liderazgo de Enseña Perú }\end{array}$ \\
\hline ) & - Tema 11: Vida de ecosistemas \\
terrestres (ODS 15) & Asociación peruana de \\
& Comunicadores - SIGNIS en América \\
& Latina y el Caribe. \\
& - Marjorie Reffray: Líder de la \\
& Asociación peruana de \\
& Comunicadores - SIGNIS Joven Perú \\
\hline - Tema 12: Reducción de las & Clara Yolks: Cantautora peruana de folk \\
desigualdades (ODS 10) & \\
\hline
\end{tabular}




\section{ANEXO 4: LISTAS DE FUENTES EN FACEBOOK Y TWITTER}

Ciudad Saludable está aquí: Parque Kennedy - Miraflores District.

17 min - Miraflores, Lima - 9

Muy contentos de haber sido parte del gran \#corsowong2019 recuperando más de 200 kgs de botellas plásticas. @wongcencosud, muchas gracias por aportar a la cadena de reciclaje 4 it $4:$ Y siguiendo el camino de estas botellas, es la Asociación de Recicladores Señor de los Milagros (ARSEMIM), operadora en Miraflores, la encargada de acopiar y darles el tratamiento respectivo $\$, Q$

Gracias a todos los equipos involucrados. \$ @ Parque Kennedy -

Miraflores District

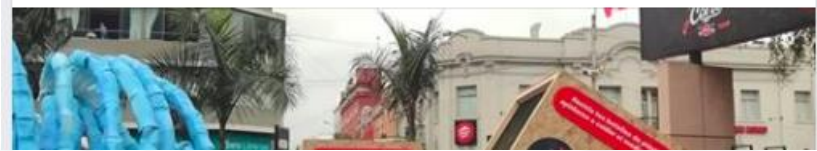

$\cdots$

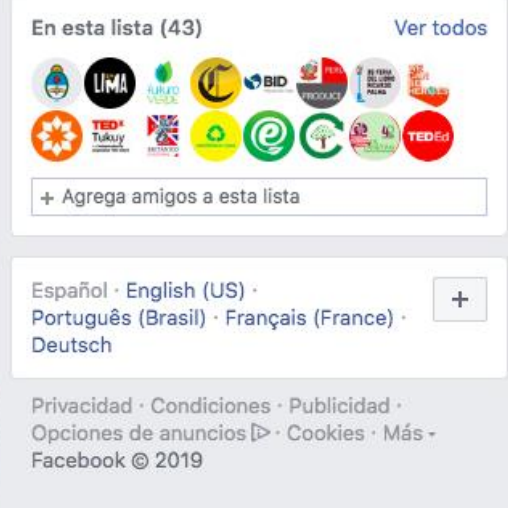

Lista de 43 páginas en Facebook con contenido relevante para nuestro podcast

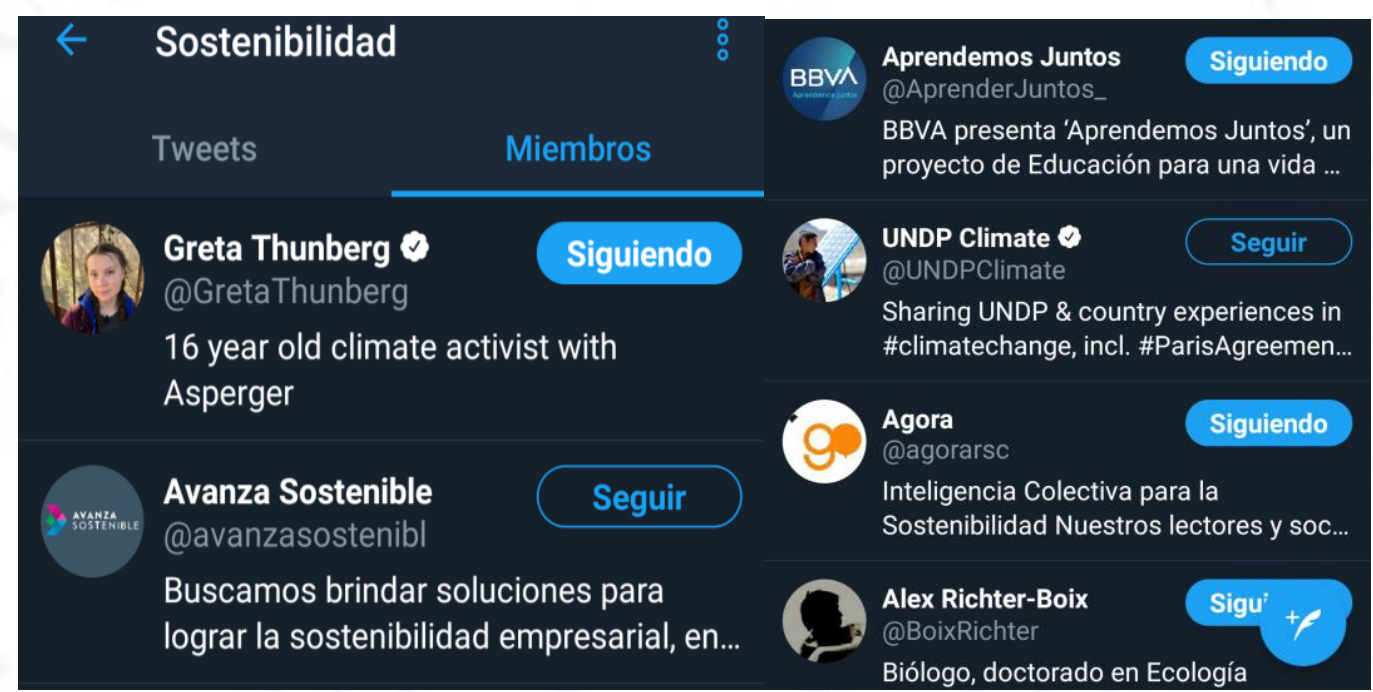

Lista de algunas de las 24 de cuentas en Twitter con contenido relevante para nuestro podcast 


\section{ANEXO 5: MANUAL DE MARCA}

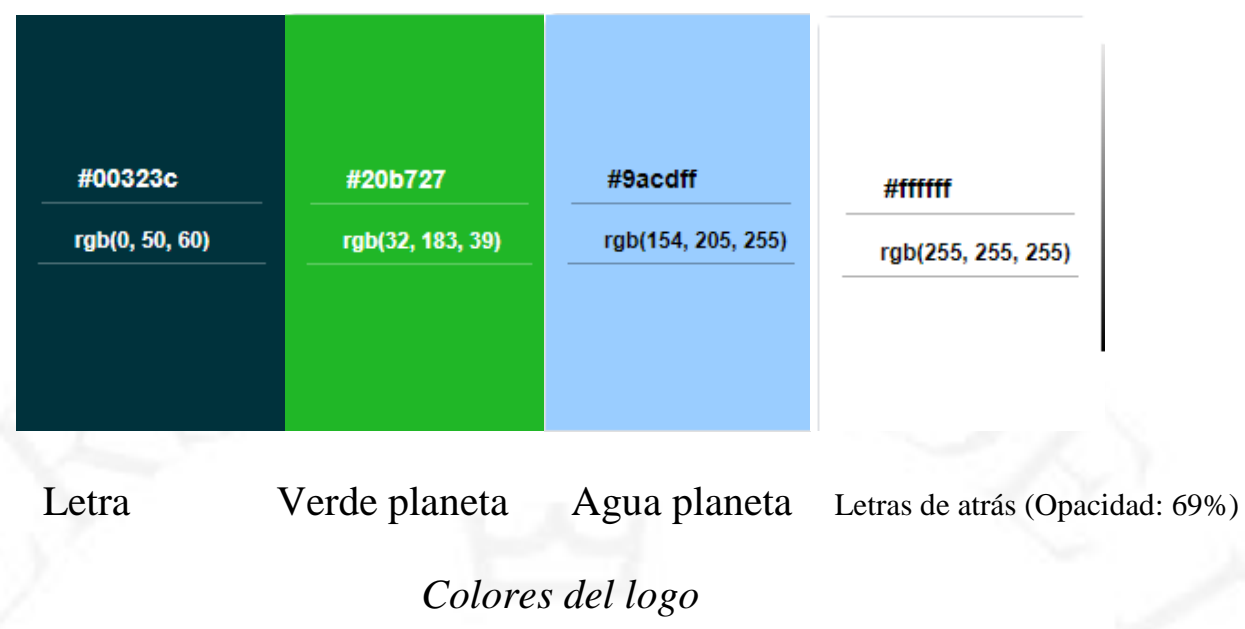

ABCDEFGHIJKLMNO PQRSTUVWXYZÀÅÉ abcdefghijklmnopq rstuvwxyzååêî1 12 34567890(\$€€.,!?)

Tipografía utilizada en el logo y publicaciones 


\section{ANEXO 6: PUBLICACIONES EN REDES SOCIALES}

\begin{tabular}{|c|c|c|c|c|c|c|c|}
\hline \multicolumn{8}{|c|}{ Plan de contenidos para redes - \#PISANDOTIERRA } \\
\hline DÍA & FECHA & HORA & CANAL & EJE & FORMATO & CONTENIDO & COPY \\
\hline Lunes & 4/11/2019 & $\begin{array}{c}8 \mathrm{pm} / 9 \\
\mathrm{pm}\end{array}$ & $\begin{array}{c}\text { Facebook e } \\
\text { Instagram }\end{array}$ & $\begin{array}{c}\text { Explicación } \\
\text { del ODS } 7\end{array}$ & Imagen & & $\begin{array}{l}\text { Esta semana en \#PisandoTierra estaremos } \\
\text { hablando del Objetivo de Desarrollo Sostenible 7: } \\
\text { Energía asequible y contaminante (\#ODS7). } \\
\text { ¿Conoces este objetivo hacia la \#Agenda2030? } \\
\text { Acá se lo explicamos \&o } \\
\text { \#EnergiaRenovable \#ONU \#PeruAgenda2030 } \\
\text { \#Agenda2030 \#ODS \#Sostenibilidad } \\
\text { \#MedioAmbiente }\end{array}$ \\
\hline Martes & $5 / 11 / 2019$ & $8 \mathrm{pm}$ & Facebook & $\begin{array}{c}\text { Compartir } \\
\text { noticia }\end{array}$ & Link & 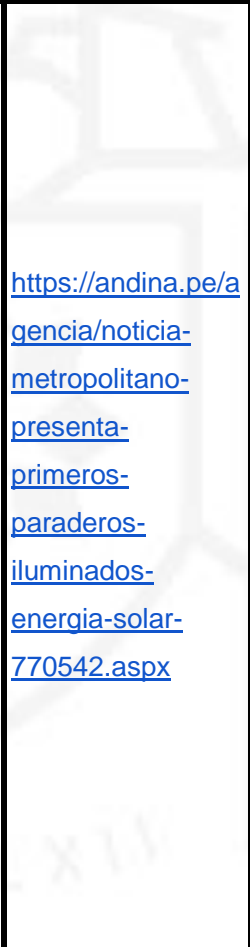 & $\begin{array}{l}\text { Kallpa Global SAC y la Municipalidad de Lima } \\
\text { instalaron paneles solares en paraderos } \\
\text { convencionales del Metropolitano. iFelicitamos esta } \\
\text { acción! La utilización de energía renovable nos } \\
\text { acerca al Objetivo de Desarrollo Sostenible 7: } \\
\text { Energía asequible y contaminante (\#ODS7). } \\
\text { ¿Conoces otros tipos de energía renovable? } \\
\text { Cuéntanos en los comentarios } \\
\text { \#Metropolitano \#TransporteUrbano \#Electricidad } \\
\text { \#PanelesSolares \#ONU \#PeruAgenda2030 } \\
\text { \#Agenda2030 } \\
\text { https://andina.pe/agencia/noticia-metropolitano- } \\
\text { presenta-primeros-paraderos-iluminados-energia- } \\
\text { solar-770542.aspx }\end{array}$ \\
\hline Miércoles & 6/11/2019 & $7 \mathrm{pm}$ & Facebook & $\begin{array}{c}\text { Perú y ODS } \\
7\end{array}$ & Link & $\begin{array}{l}\text { https://stories.und } \\
\text { p.org/crecer-con- } \\
\underline{\text { el-sol }}\end{array}$ & $\begin{array}{l}\text { Compartimos un proyecto del Programa de las } \\
\text { Naciones Unidas para el Desarrollo - PNUD que } \\
\text { permite la utilización de energía renovable en la } \\
\text { provincia de Aricota, el cual nos enseña que "(...) las } \\
\text { energías limpias también son una oportunidad para } \\
\text { los bionegocios en las comunidades más } \\
\text { vulnerables." }\end{array}$ \\
\hline & & & & & & & \\
\hline
\end{tabular}




\begin{tabular}{|c|c|c|c|c|c|c|c|}
\hline & & & & & & & $\begin{array}{l}\text { :): } \\
\text { https://stories.undp.org/crecer-con-el-sol } \\
\text { \#Energia \#ODS7 \#MedioAmbiente \#Panelessolares } \\
\text { \#Bionegocio \#Ecoturismo }\end{array}$ \\
\hline Miércoles & $6 / 11 / 2019$ & $3 \mathrm{pm}$ & Instagram & $\begin{array}{c}\text { Perú y ODS } \\
7\end{array}$ & Reposteo & $\begin{array}{l}\text { https://www.instag } \\
\text { ram.com/p/B4S0Z } \\
\text { WQBCGd/?igshid } \\
=15 q 1 \text { arf068opd } \\
\end{array}$ & $\begin{array}{l}\text { En Chulpia, Puno se ha construido el primer bote } \\
\text { con paneles solares en una zona altoandina. } \\
\text { ¿Conoces otro proyecto del PNUD sobre energía } \\
\text { renovable? Link en la bio } \\
\text { \#Energia \#ODS7 \#MedioAmbiente }\end{array}$ \\
\hline Jueves & 7/11/2019 & $6 \mathrm{pm}$ & Instagram & $\begin{array}{c}\text { Infografía } \\
\text { centrales } \\
\text { de energia }\end{array}$ & $\begin{array}{c}\text { Imagen/Co } \\
\text { mpartir } \\
\text { contenido } \\
\text { en historia } \\
\text { y una } \\
\text { encuesta }\end{array}$ & & 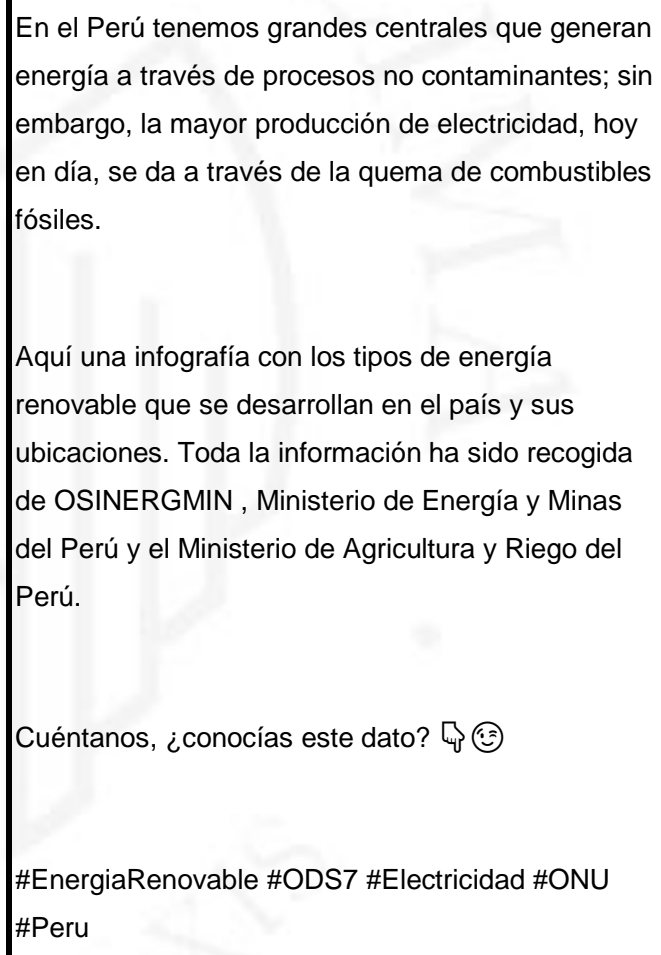 \\
\hline Viernes & 8/11/2019 & $\begin{array}{c}8 \mathrm{pm} / 3 \\
\mathrm{pm}\end{array}$ & $\begin{array}{c}\text { Facebook e } \\
\text { Instagram } \\
\text { (Historia) }\end{array}$ & $\begin{array}{c}\text { Recordatori } \\
\text { o del } \\
\text { programa } \\
\# 2\end{array}$ & $\begin{array}{l}\text { Link del } \\
\text { episodio }\end{array}$ & $\begin{array}{l}\frac{\text { https://open.spotif }}{\text { y.com/episode/3aJ }} \\
\frac{\text { UF3yrzbJoXaaOC }}{\text { di4Zh?si=rk1ghWi }} \\
\frac{\text { 6RKCOpRTtS6Ub }}{\underline{m Q}}\end{array}$ & $\begin{array}{l}\text { Esta semana hemos compartido información sobre } \\
\text { el \#ODS7: Energía asequible y no contaminante. En } \\
\text { \#PisandoTierra desarrollamos ese objetivo de la } \\
\text { \#Agenda2030 en el segundo programa de nuestro } \\
\text { podcast. 囚ロ } \\
\text { Además, conversamos con Robinson Calderón de } \\
\text { Innovación ambiental, una empresa peruana que } \\
\text { apuesta por la implementación de más energía } \\
\text { renovable en nuestra sociedad. }\end{array}$ \\
\hline
\end{tabular}




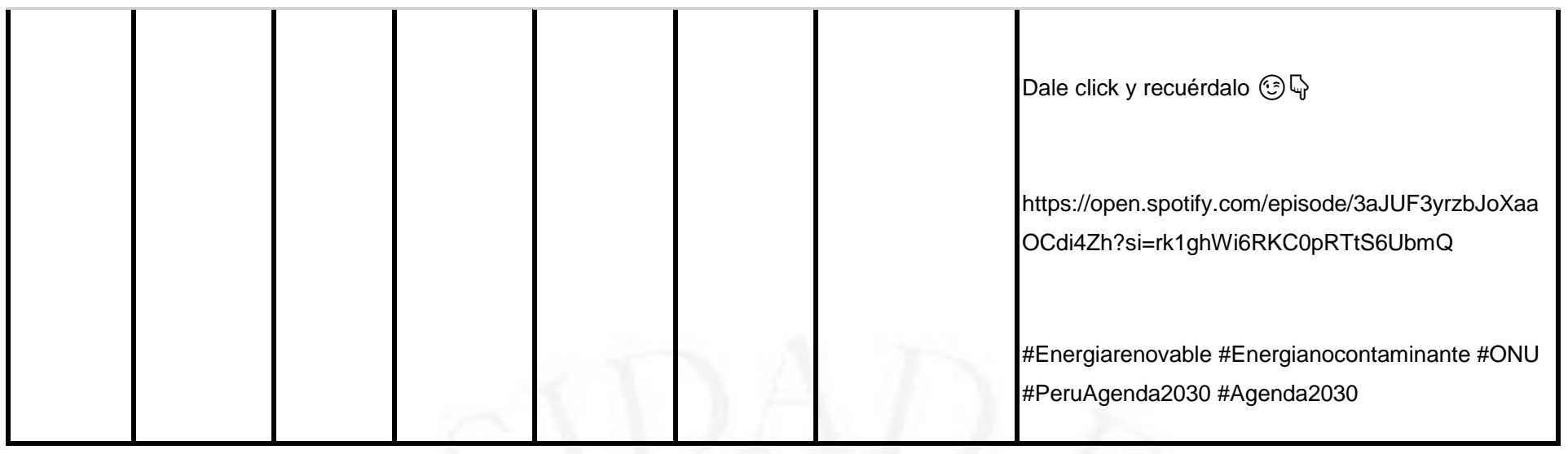

Cronograma de contenido para redes sociales 


\section{ANEXO 7: PUBLICACIONES DE SORTEOS}

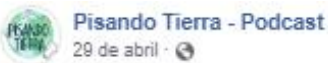

Este viernes \#PisandoTierra llega a SoundCloud para compartir temas sobre \#medioambiente, \#ecología y \#sostenibilidad - $^{-}$

Te prometimos sorpresas, iy aquí las tenemos!

Vamos a sortear un premio entre los usuarios que compartan nuestro primer capítulo e incluyan un comentario sobre lo que más les interesó tras la escucha $4:$

¿Estás listo?
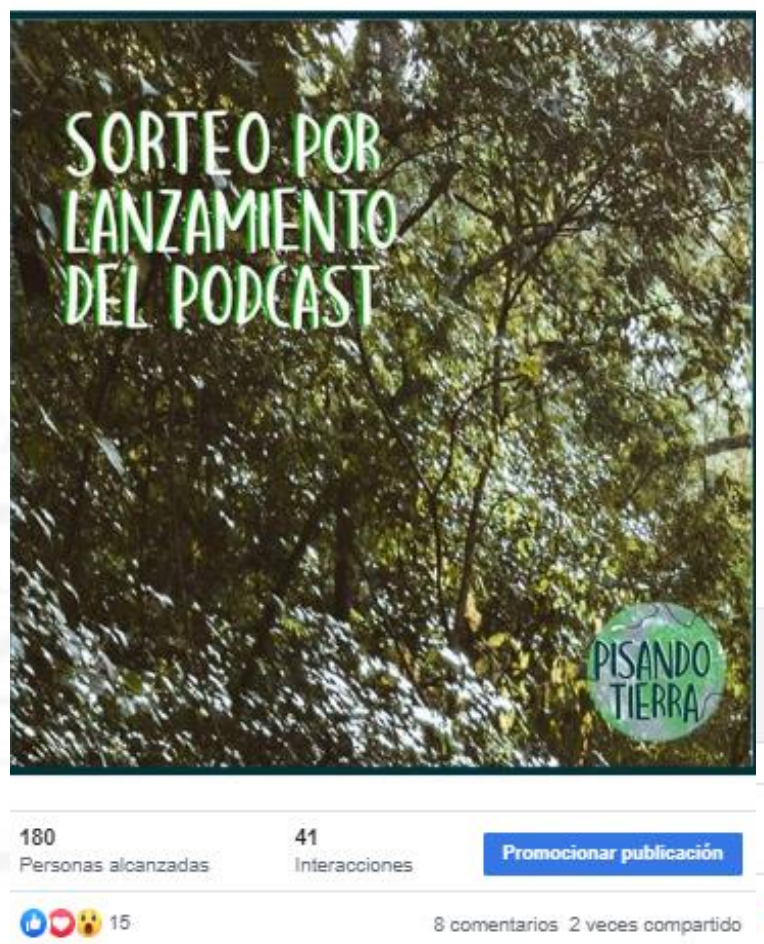

-.. $\rightarrow$ Pisando Tierra - Podcast 3 de mayo- 6 \#ESTRENO

¡Ya está en Soundcloud nuestro primer podcast de \#PisandoTierra! † Recuerda que para acceder al sorteo del pack ecoamigable debes: 1. Darle like a Pisando Tierra - Podcast

2. Compartir este link (de forma pública) en Facebook con la info que te pareció más interesante de este capítulo, y

3. Usar el HT \#PisandoTierra en la publicación

Recuerda que revisaremos que hayan cumplido todos los pasos antes del sorteo \& Válido solo para Lima.

$\rightarrow$ Tienes hasta el viernes 10 de mayo para participar $\rightarrow$

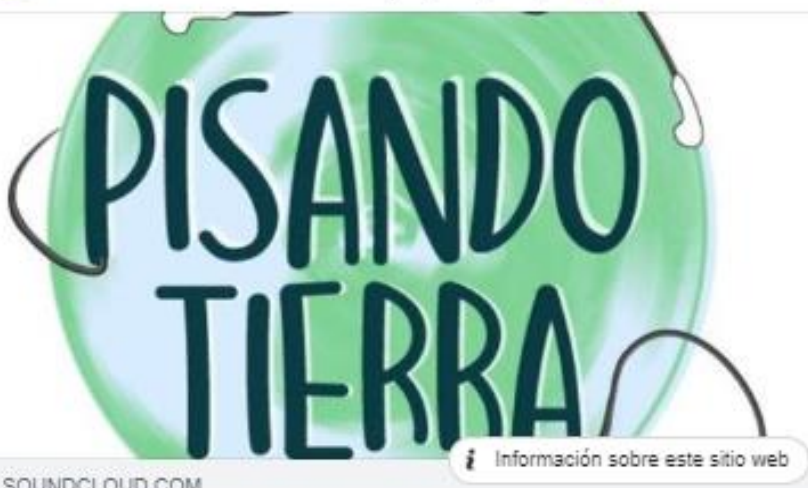

SOUNDCLOUD.COM

Pisando Tierra

Este espacio ha sido creado para aportar a temas de sostenibilidad y poder

1.545

Personas alcanzadas Interacciones

Promocionar publicación

00:

7 veces compartido

Primer sorteo

4it. Pisando Tierra - Podcast 3 de junio 9

¡No te olvides que tenemos un sorteo!

\#SORTEOPISANDOTIERRA.

\#Pisando Tierra tiene un sorteo! Pueden participar hasta el día martes 04/06 11:58 pm

Los pasos aqui

1. Darle Me Gusta a Pisando Tierra - Podcast 4

2. Enviar un audio al messenger de Pisando Tierra - Podcast sobre ¿Qué es para ti la huella Medioambiental? y algo que te guste del programa. 3. Compartir desde Spotify. Soundcloud o Noox uno de nuestros programas en Facebook de forma pública, etiquetándonos y poniendo el \#SorteoPisandoTierra

Y... Iya está!

Además, jtus audios podrán aparecer en nuestro siguiente programa!

No se olviden que \#PisandoTierra está en Spotify. Noox y Soundcloud: https:/t.co/0QS7021ncR

https $/ /$ t.co/8g 4 odgpSEg

https//t.co/KOcOmvfh 0

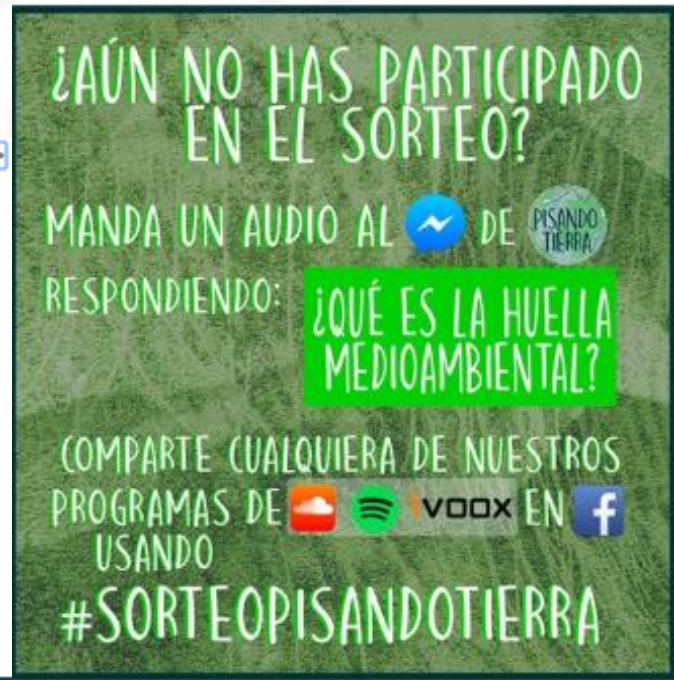

Segundo sorteo 


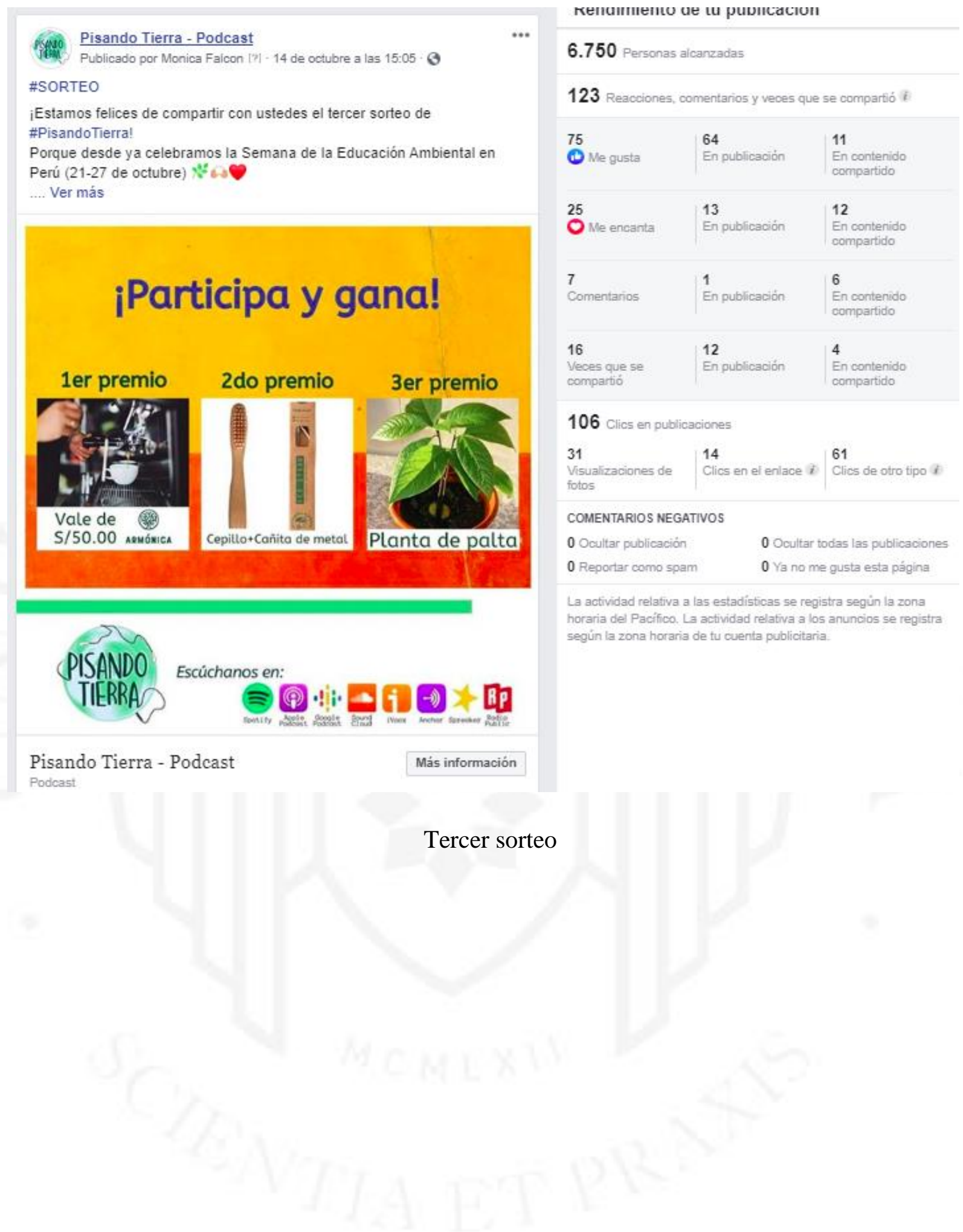




\section{ANEXO 8: CONTENIDO COMPARTIDO}
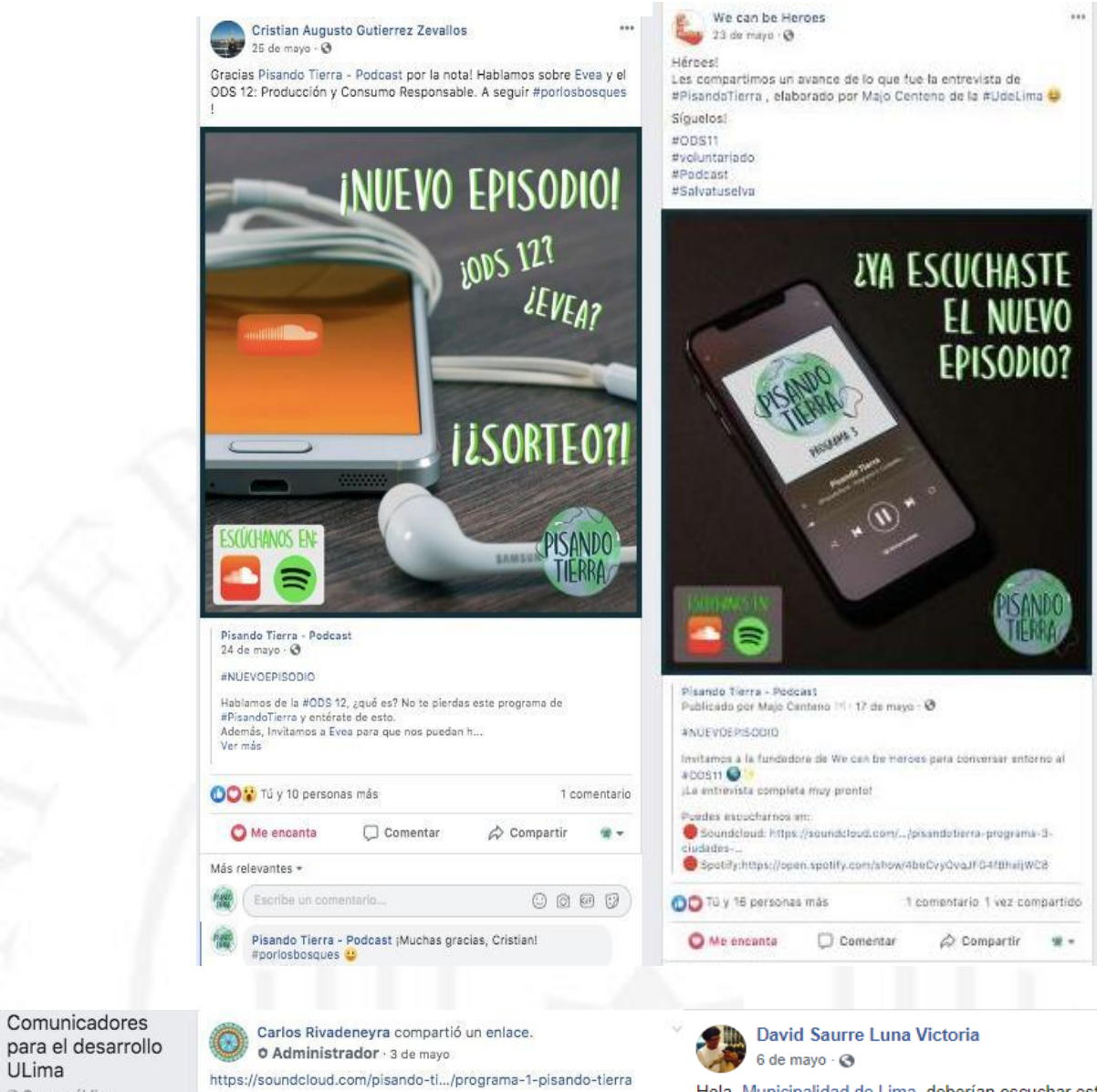

9.7. David Saurre Luna Victoria https://soundcl
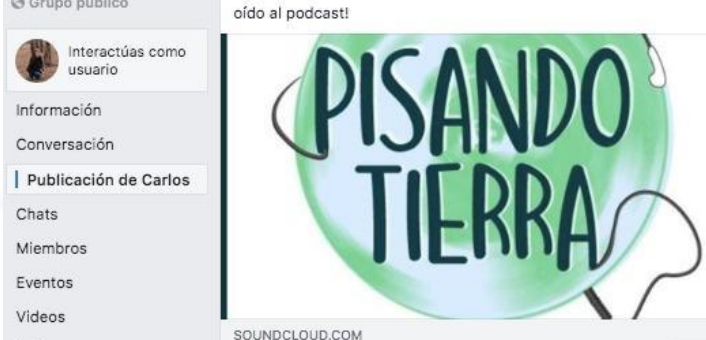

SOUnDCLOUD CON

Programa 1 - Pisando Tierra

Primer capitulo de \#PisandoTierra. Hoy introducimos al.

Recomendaciones

Buscar en este grupo Q

$00^{2}$

(7)

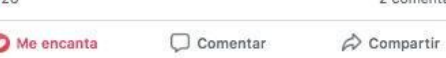

SOUNDCLOUD.COM

Pisando Tierra

i Información sobre este sitio we

Accesos directos

(1) voluntarios Creando $\mathrm{S}$

Matoc

Majo Centeno Estrenamos el segundo capítulo este viernes $\&$

cio ha sido creado para aportar a temas de...

Karla Alejandra y 2 personas más

Publicaciones en Facebook 

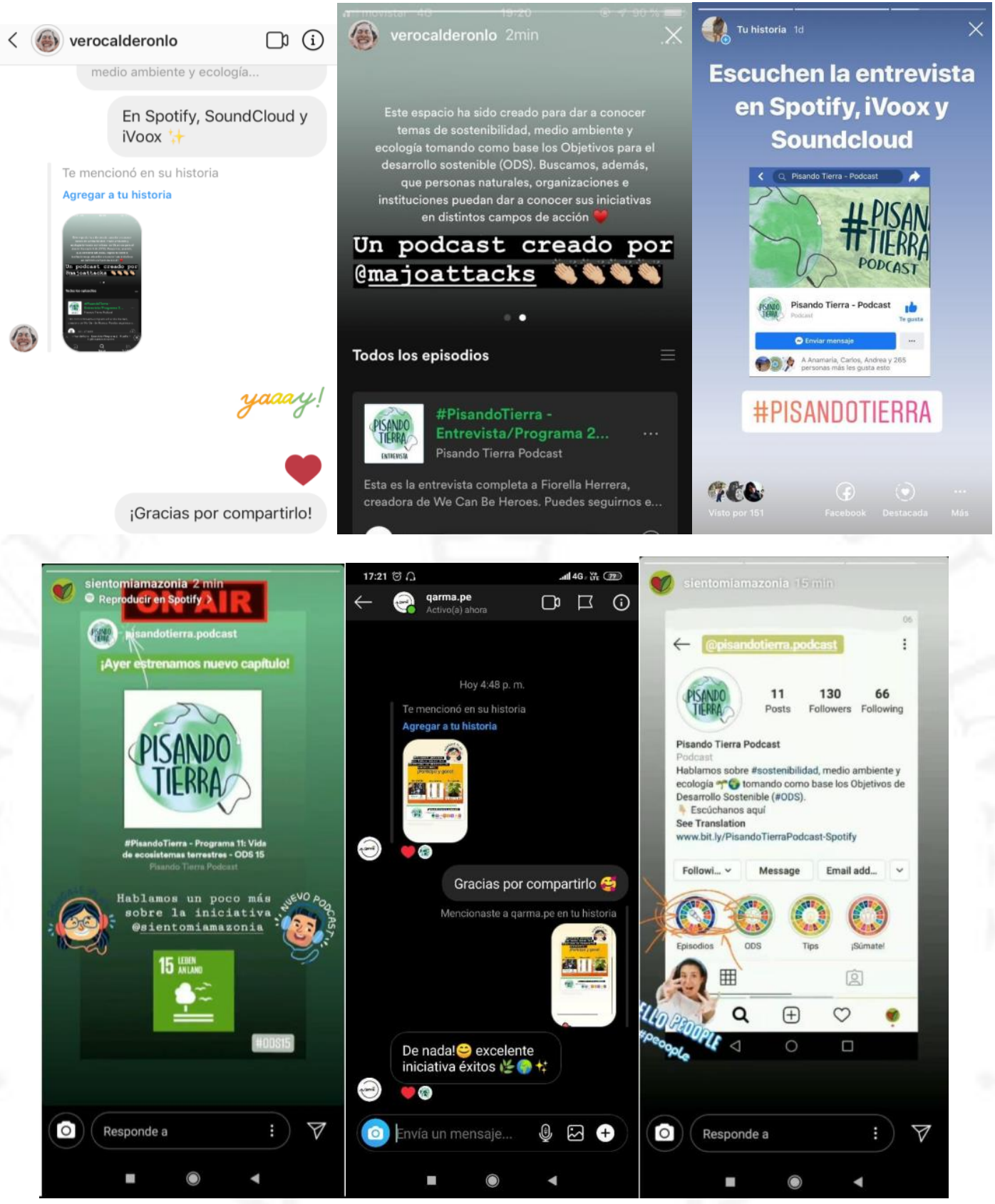

Publicaciones en Instagram 
Hola a todos:

Quiero compartir con ustedes una noticia que me ha alegrado mucho: aceptaron mi \#podcast como proyecto para licenciarme.

Gracias al taller de Podcasting y radio que llevé en mis últimos ciclos de carrera. cambié una tesis de investigación que tenia casi lista por un producto que pueda brindarme mayor impacto social y me permita aprender aún más sobre \#sostenibilidad.

En lineas generales, junto a Monica Falcon, orientamos el contenido de cada episodio de Pisando Tierra a uno o más Objetivos de Desarrollo Sostenible. Para ello, encontramos emprendimientos u organizaciones que ya se encuentren realizando alguna acción ligada a los \#ODS y entrevistamos a algún representante. De esta manera damos a conocer que desde Perú os estamos avanzando más y más hacia la \#Agenda2030

Pueden encontrar. Pisando Tierra en \#5potify, \#Soundcloud y otras 6 plataformas gratuitas más.

Además, hemos estrenado cuenta en Instagram: https://nkd.in/gigV8UQ

Si alguno tiene feedback es más que bienvenido y si conocen algún emprendimiento u organización que creen que podriamos entrevistar, también lo agradeceré mucho +

\#podcasting \#SDG \#Peru \#DesarrolloSostenible

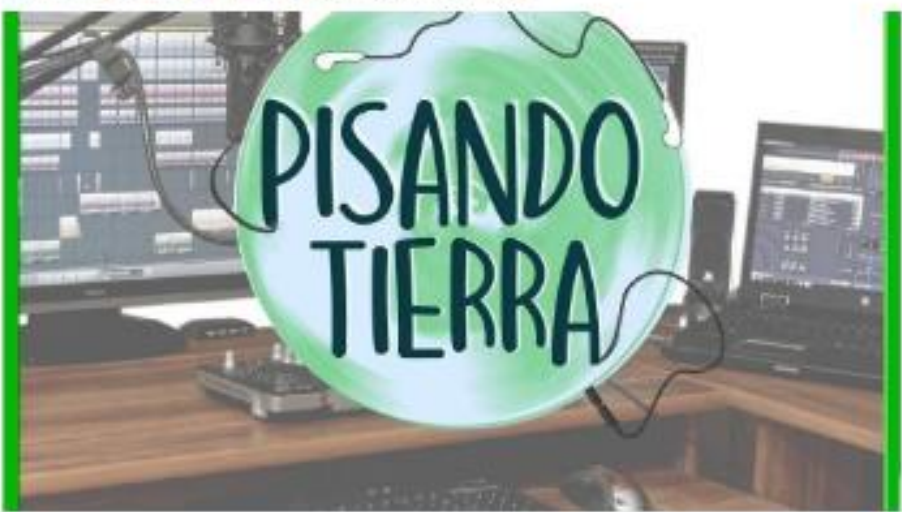

Pisando Tierra Podcast on Instagram: "iHola a todos! Somos \#pisandotierra, un podcast que habla sobre los \#ODS (Objetivos de Desarrollo Sostenible) con.

instagramicart

- $054-14$ comentario

○ $\odot 54-14$ comentarios

Publicaciones en LinkedIn 


\section{ANEXO 9: PUBLICACIONES COMPARTIDAS DE LAS GANADORAS DE LOS CONCURSOS}

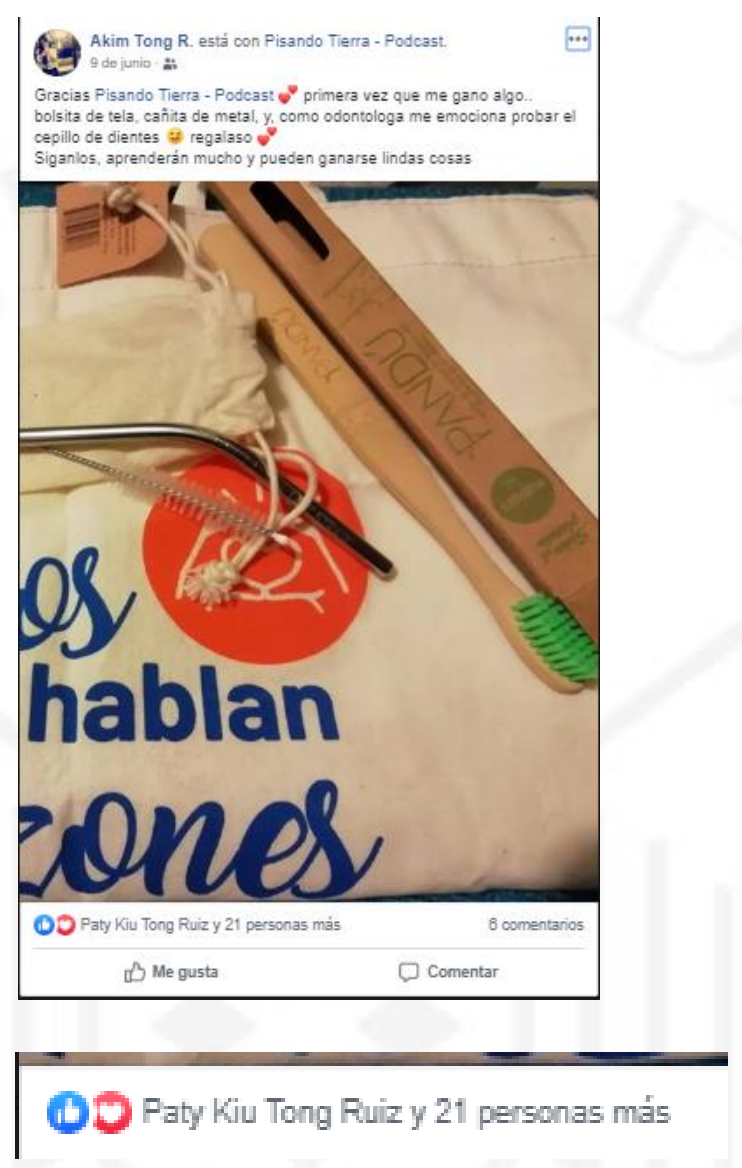

Ganadora del primer concurso 


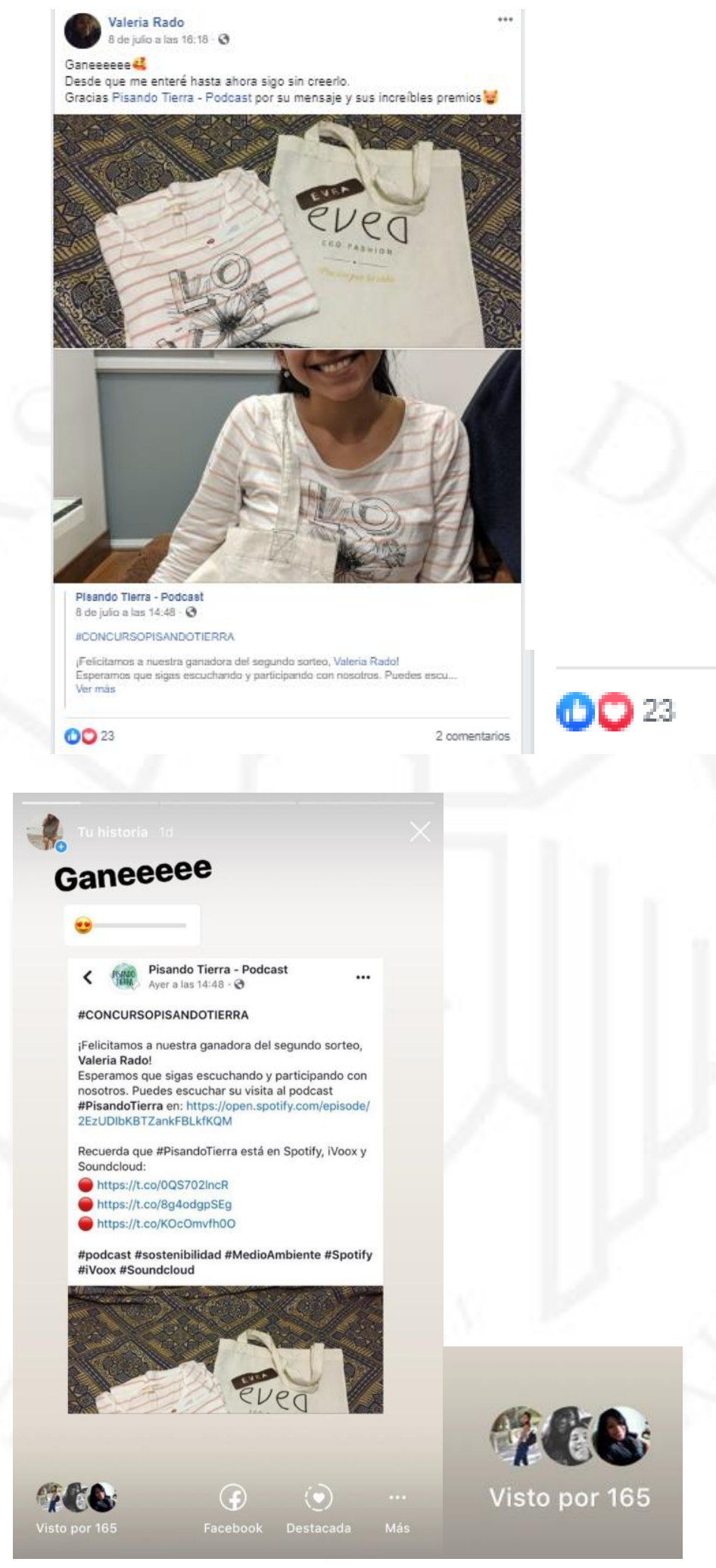

Ganadora del segundo concurso 


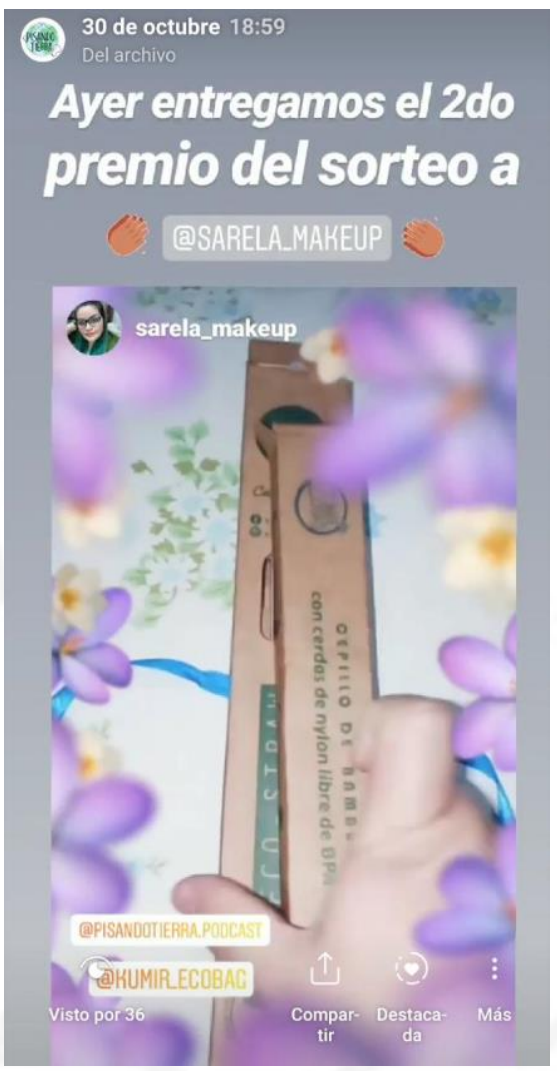

Una de las ganadoras del tercer concurso 